The Astrophysical Journal SUPPLEMENT SERIES, 120:131-145, 1999 January

(C) 1999. The American Astrnomical Association. All rights reserved. Printed in U.S.A.

\title{
ELECTRON-ION RECOMBINATION RATE COEFFICIENTS, PHOTOIONIZATION CROSS SECTIONS, AND IONIZATION FRACTIONS FOR ASTROPHYSICALLY ABUNDANT ELEMENTS.
}

\section{OXYGEN IONS}

\author{
Sultana N. NaHAR \\ Department of Astronomy, Ohio State University, Columbus, OH 43210 \\ Received 1998 May 13; accepted 1998 August 10
}

\begin{abstract}
A comprehensive and self-consistent set of new atomic data for photoionization cross sections, $\sigma_{\mathrm{PI}}$, and total unified recombination rate coefficients, $\alpha_{R}(T)$, of oxygen ions are obtained. The calculations are carried out in the close coupling approximation employing the $\boldsymbol{R}$-matrix method. The unified treatment of total recombination includes both the radiative and dielectronic processes. The analysis of astrophysical spectra and ionization balance requires atomic data for all ionization stages of an element, and the accuracy depends on the self-consistency and completeness of data. In the present work the criterion of self-consistency between the rates for the inverse processes of photoionization and recombination is satisfied in an ab initio manner by employing an identical set of eigenfunction expansions in the calculations for both atomic processes. State-specific recombination rate coefficients are also presented for a large number of bound states. As a first application, the present $\alpha_{R}(T)$ are used to obtain ionization fractions of oxygen ions in plasmas in coronal equilibrium. Ionization fractions in photoionization equilibrium can be readily obtained by employing the present data for the total $\sigma_{\mathrm{PI}}$ and for $\alpha_{R}(T)$.

Subject headings: atomic data - atomic processes
\end{abstract}

\section{INTRODUCTION}

The aim of the present series of studies, as discussed in detail in the first paper of the series (Nahar \& Pradhan 1997, hereafter NP1), is to provide a more complete and self-consistent set of atomic data for accurate ionization balance calculations for plasma diagnostics. The first paper presented photoionization cross sections, recombination rates, and ionization fractions for all ionization stages of carbon and nitrogen. In our previous work the calculations were done mainly along isoelectronic sequences of elements to facilitate the atomic algebraic manipulations. However, for determination of quantities such as ionization fractions, data are required for all ionization stages of an element. The uncertainties in the atomic data for the inverse processes of photoionization and recombination are minimized through a self-consistent treatment of both processes. Prior to this work for $\mathrm{O}$ ions, and the $\mathrm{C}$ and $\mathrm{N}$ ions reported in NP1, these parameters were calculated using different approximations of varying uncertainties in different temperature regions. In the present work for photoionization and recombination the same set of atomic wave function expansions for a given ion are used, including the coupling effects between the continuum and the bound states. Results are presented for all oxygen ions, $\mathrm{O}$ I, O II, O III, O IV, O v, O vI, $\mathrm{O}$ VII, and $\mathrm{O}$ VIII. Because of the volume of quantities, the details of the photoionization cross sections are reported separately (Nahar 1998). The total recombination rate coefficients, $\alpha_{R}(T)$, along with state-specific partial rates for a large number of bound states, are presented herein. All results being reported are new except for some of the recombination rates for $\mathrm{O}$ III that were published earlier (Nahar 1995, 1996a) but are included here for completeness. To demonstrate the effect of the new data on ionization calculations in plasmas, the $\alpha_{R}(T)$ are used to compute ionization fractions in collisional ("coronal") equilibrium and compared with a recent work (Sutherland \& Dopita 1993).

\section{THEORY AND COMPUTATIONS}

The calculations for both the photoionization and recombination rate coefficients are carried out in the close coupling (CC) approximation employing the $\boldsymbol{R}$-matrix method. The theoretical details are described in earlier publications, e.g., calculations of photoionization cross sections are described in the Opacity Project (OP) paper (Seaton 1987). The unified treatment for the total recombination rate coefficients is described in Nahar \& Pradhan (1994, hereafter NP2; 1995, hereafter NP3). The cross sections are calculated using the $\boldsymbol{R}$-matrix package of codes developed for the OP (Berrington et al. 1987), and extended for the Iron Project (IP) (Hummer et al. 1993). Further extensions for recombination work were implemented and are described in NP2 and NP3. For the highly charged He-like ion $\mathrm{O}$ VII, fine-structure effects are also investigated using the Breit-Pauli version of the codes in intermediate coupling (Scott \& Taylor 1982; Hummer et al. 1993), which have been extended to include radiation damping of resonances (Zhang \& Pradhan 1997; Pradhan \& Zhang 1997). The unified treatment employed for recombination subsumes both the radiative recombination (RR) and dielectronic recombination (DR) processes in a unified manner, in contrast to the previous calculations that treated the RR and the DR separately using different methods. Some of the main points relevant to the present work on oxygen ions are discussed below.

In the CC approximation, the wave function expansion for an electron + ion system of a given symmetry is characterized by the total spin $S$, the total angular momentum $L$, and parity $\pi$. For each $S L \pi$ the wave function expansion, $\Psi(E)$, is expressed in terms of the $N$-electron "core" or the "target" states, $\chi_{i}$, coupled to a "free"-electron wave function, $\theta_{i}$, as

$$
\Psi(E)=A \sum_{i} \chi_{i} \theta_{i}+\sum_{j} c_{j} \Phi_{j}
$$


where the electron-electron correlation effects are treated through couplings among all channels corresponding to the target states included. The functions $\Phi_{j}$ in the second term are the bound channel wave functions of the $(N+1)$-electron system representing short-range correlations not included in the first term on the right-hand side, and compensate for the orthogonality conditions for the oneelectron orbital basis set. It is important to optimize the wave function through a proper choice of the $N$-electron target states in the first expansion, and the $(N+1)$-electron configurations in the second expansion, in order to obtain complete and accurate data and to delineate the detailed features in the cross sections.

The wave function expansion for each oxygen ion and computational details of the atomic calculations for photoionization cross sections are described in Nahar (1998), including discussions of the detailed features in the cross sections. Discussions in Nahar (1998) concern mainly the total photoionization cross sections for leaving the residual ion in various target ion states. However, computations of recombination rate coefficients require partial photoionization cross sections leaving the residual ion in the ground state of the target ion. Partial photoionization cross sections, $\sigma_{\mathrm{PI}}$, of a large number of bound states for each oxygen ion are obtained. Illustrative $\sigma_{\mathrm{PI}}$ of some excited states (not presented in Nahar 1998) relevant to the recombination rates are discussed below. Coupling of channels result in resonances in $\sigma_{\mathrm{PI}}$ at energies of Rydberg series of quasibound or autoionizing states converging onto excited states of the core or the target ion. The positions, heights, and shapes of the broad resonances affect the recombination rate coefficients, $\alpha_{R}(T)$, and therefore the resonances near the ionization threshold need to be well resolved.

The recombination cross sections, $\sigma_{\mathrm{RC}}$, can be obtained from $\sigma_{\mathrm{PI}}$ through the principle of detailed balance as

$$
\sigma_{\mathrm{RC}}=\frac{g_{i}}{g_{f}} \frac{h^{2} v^{2}}{m^{2} v^{2} c^{2}} \sigma_{\mathrm{PI}},
$$

where $g_{i}$ and $g_{f}$ are the statistical weight factors of the initial and final states, respectively, $v$ is the velocity of the photoelectron, and $v$ is the photon frequency. The recombination rate coefficient at a given temperature is given by averaging $\sigma_{\mathrm{RC}}(T)$ over the Maxwellian distribution of electrons, $f(v)$, as

$$
\begin{aligned}
\alpha_{R}(T) & =\int_{0}^{\infty} v f(v) \sigma_{\mathrm{RC}} d v \\
& =\frac{g_{i}}{g_{j}} \frac{2}{k T \sqrt{2 \pi m^{3} k c^{2} T}} \int_{0}^{\infty} E^{2} \sigma_{\mathrm{PI}}(\epsilon) e^{-\epsilon / k T} d \epsilon,
\end{aligned}
$$

where $E=\hbar \omega=\epsilon+I_{p}, \epsilon$ is the photoelectron energy, and $I_{p}$ is the ionization potential. As the cross sections include the detailed structures of autoionizing resonances, the sum of individual rates of the bound states corresponds to inclusion of both the RR and the DR in an unified and ab initio manner.

Electron recombination to a target ion can take place to an infinite number of bound states of the recombined ion. In the unified treatment the total recombination rate coefficient $\alpha_{R}(T)$ is a sum over all the states of the recombined ion. With the recombining ion assumed to be in the ground state, the computations divide the recombined $n S L \pi$ states into two groups: low- $n$ bound states with $n \leq n_{0}$ (group A) and high- $n$ states with $n_{0}<n<\infty$ (group B), i.e.,

$$
\alpha_{R}=\sum_{n \leq n_{0}} \alpha(n S L \pi)+\sum_{n=n_{0}}^{\infty} \alpha_{\mathrm{DR}},
$$

where $n_{0}$ is typically equal to 10 . The sum of individual rates obtained from the partial photoionization cross sections corresponds to contributions of the low- $n$ bound states of group A. The total number of bound states of group A can be quite large. This number, $N_{b}$, for states that couple to the target ground state and for which values of $\sigma_{\mathrm{PI}}$ are obtained for each oxygen ion, is specified in Table 1. Group B states in the second term of equation (4) are treated through dielectronic recombination implementing the precise theory of DR by Bell \& Seaton (1985). These states belong to small energy regions below excitation thresholds of the target ion. The contributions are mainly through dielectronic recombination from resonances with $n>n_{0}$ that are narrow and dense. It is a good approximation to assume that the background nonresonant contribution is negligible compared to DR in these regions.

However, the background nonresonant contributions (RR type) of high- $n$ states $10 \leq n_{0} \leq \infty$ (the "top-up" part) are also included in the total $\alpha_{R}(T)$. These are obtained in the hydrogenic approximation as described in Nahar (1996b). The contributions are significant in the very low temperature region $T<1000 \mathrm{~K}$, but negligible at higher temperatures. The recombination at very low temperatures is dominated by the direct, nonresonant recombination ( $R R$ type) to the infinite number of high- $n$ states where the electron energies are too low to excite the resonances.

Computations of the state-specific partial recombination rate coefficients of the group A bound states of the recombined electron + ion system are carried out using the code RECOMB (Nahar 1996b). Although a large number of bound states are included in the first sum of equation (4), a few equivalent electron states are often the dominant contributors to the recombination rates over a wide range of temperatures. Photoionization cross sections of these states have comparatively smooth and large backgrounds that contribute considerably to $\alpha_{R}(T)$. Two such examples, which dominate the recombination of $\mathrm{O}$ II, are $\sigma_{\mathrm{PI}}$ for equivalent electron bound states $2 s^{2} 2 p^{3}\left({ }^{2} D^{o}\right)$ and $2 s^{2} 2 p^{3}\left({ }^{2} P^{o}\right)$ shown in Figures $1 a$ and $1 b$. Both the ${ }^{2} D^{o}$ and ${ }^{2} P^{o}$ states show dense resonances in the low-energy region, but it is their high background cross sections that dominate the recombination cross sections even at high temperatures. Another important feature is shown in Figure $1 c$ presenting $\sigma_{\mathrm{PI}}$ of a dominant equivalent state of O II, $2 s 2 p^{4}\left({ }^{4} P\right)$. It may be noted that in the low-energy region of this state, there are extensive autoionizing resonances with almost no background. In a direct ionization, $2 s 2 p^{4}$ would not ionize to the $\mathrm{O}$ III ground state, $2 s^{2} 2 p^{2}\left({ }^{3} P\right)$, but would ionize into the excited $2 s 2 p^{3}\left({ }^{3} D^{o}\right)$ state of $\mathrm{O}$ III at a photon energy of 2.6 rydbergs (indicated by the arrow in Fig. 1c). Hence, in calculations where no autoionizing channels are included, such as in the central field approximation (e.g., Reilman \& Manson 1979), this state would show zero cross section below the threshold of the excited state ${ }^{3} D^{o}$. However, the large resonances due to coupling of excited states, as in the present calculations, make significant contributions to the recombination cross sections.

In addition to the usual narrow Rydberg resonances, the photoexcitation of core (PEC), with the outer electron as a spectator, can introduce resonances in the cross sections 
TABLE 1

State-SPECIFIC ReCombination Rate Coefficients for Four Temperatures ${ }^{\mathrm{a}}$

\begin{tabular}{|c|c|c|c|c|c|c|c|c|c|c|c|}
\hline \multicolumn{3}{|l|}{$100 \mathrm{~K}$} & \multicolumn{3}{|c|}{$1000 \mathrm{~K}$} & \multicolumn{3}{|c|}{$10,000 \mathrm{~K}$} & \multicolumn{3}{|c|}{$50,000 \mathrm{~K}$} \\
\hline State & & $\alpha_{R}$ & State & & $\alpha_{R}$ & State & & $\alpha_{R}$ & State & & $\alpha_{R}$ \\
\hline \multicolumn{12}{|c|}{ O I: $g=\left(2 s^{2} 2 p^{4}\right)^{3} P^{e} ; N_{b}=104$} \\
\hline $2 s^{2} 2 p^{4}$ & ${ }^{3} P^{e}$ & $1.19-12$ & $2 s^{2} 2 p^{4}$ & ${ }^{3} P^{e}$ & $3.82-13$ & $2 s^{2} 2 p^{4}$ & ${ }^{3} P^{e}$ & $1.57-13$ & $2 s^{2} 2 p^{4}$ & ${ }^{3} P^{e}$ & $9.98-14$ \\
\hline $2 s^{2} 2 p^{34} S^{o} 3 d$ & ${ }^{5} D^{o}$ & $2.19-13$ & $2 s^{2} 2 p^{3}{ }^{4} S^{o} 3 d$ & ${ }^{5} D^{o}$ & $6.55-14$ & $2 s^{2} 2 p^{34} S^{o} 3 d$ & ${ }^{5} D^{o}$ & $1.41-14$ & $2 s^{2} 2 p^{3}{ }^{4} S^{o} 3 d$ & ${ }^{5} D^{o}$ & $1.02-14$ \\
\hline $2 s^{2} 2 p^{34} S^{o} 4 d$ & ${ }^{5} D^{o}$ & $1.27-13$ & $2 s^{2} 2 p^{34} S^{o} 4 d$ & ${ }^{5} D^{o}$ & $3.80-14$ & $2 s^{2} 2 p^{3}{ }^{4} S^{o} 4 d$ & ${ }^{5} D^{o}$ & $8.27-15$ & $2 s^{2} 2 p^{3}{ }^{4} S^{o} 3 p$ & ${ }^{5} P^{e}$ & $9.94-15$ \\
\hline $2 s^{2} 2 p^{3}{ }^{4} S^{o} 3 d$ & ${ }^{3} D^{o}$ & $1.18-13$ & $2 s^{2} 2 p^{3}{ }^{4} S^{o} 3 d$ & ${ }^{3} D^{o}$ & $3.49-14$ & $2 s^{2} 2 p^{3}{ }^{4} S^{o} 3 d$ & ${ }^{3} D^{o}$ & $7.32-15$ & $2 s^{2} 2 p^{3}{ }^{4} S^{o} 4 d$ & ${ }^{5} D^{o}$ & $8.77-15$ \\
\hline $2 s^{2} 2 p^{3}{ }^{4} S^{o} 3 p$ & ${ }^{5} P^{e}$ & $9.37-14$ & $2 s^{2} 2 p^{3}{ }^{4} S^{o} 3 p$ & ${ }^{5} P^{e}$ & $2.76-14$ & $2 s^{2} 2 p^{32} D^{o} 3 s$ & ${ }^{3} D^{o}$ & $6.95-15$ & $2 s^{2} 2 p^{3}{ }^{4} S^{o} 5 d$ & ${ }^{5} D^{o}$ & $7.41-15$ \\
\hline $2 s^{2} 2 p^{3}{ }^{\circ} S^{o} f$ & ${ }^{5} F^{e}$ & $8.48-14$ & $2 s^{2} 2 p^{3}{ }^{4} S^{o} f f$ & ${ }^{5} F^{e}$ & $2.33-14$ & $2 s^{2} 2 p^{3}{ }^{4} S^{o} 3 p$ & ${ }^{5} P^{e}$ & $5.82-15$ & $2 s^{2} 2 p^{3}{ }^{4} S^{o} 4 d$ & ${ }^{3} D^{o}$ & $6.34-15$ \\
\hline $2 s^{2} 2 p^{3}{ }^{o} 5 f$ & ${ }^{5} F^{e}$ & $7.48-14$ & $2 s^{2} 2 p^{34} S^{o} 5 d$ & ${ }^{5} D^{o}$ & $2.20-14$ & $2 s^{2} 2 p^{3}{ }^{4} S^{o} 5 d$ & ${ }^{5} D^{o}$ & $4.81-15$ & $2 s^{2} 2 p^{3}{ }^{\circ} S^{o} 3 s$ & ${ }^{5} S^{o}$ & $6.13-15$ \\
\hline $2 s^{2} 2 p^{3}{ }^{4} S^{o} 5 d$ & ${ }^{5} D^{o}$ & $7.32-14$ & $2 s^{2} 2 p^{3}{ }^{4} S^{o} 4 d$ & ${ }^{3} D^{o}$ & $2.11-14$ & $2 s^{2} 2 p^{3}{ }^{4} s^{o} 4 d$ & ${ }^{3} D^{o}$ & $4.68-15$ & $2 s^{2} 2 p^{3}{ }^{4} S^{o} 3 d$ & ${ }^{3} D^{o}$ & $5.63-15$ \\
\hline $2 s^{2} 2 p^{3}{ }^{4} S^{o} 4 d$ & ${ }^{3} D^{o}$ & $7.08-14$ & $2 s^{2} 2 p^{3}{ }^{4} S^{o} 5 f$ & ${ }^{5} F^{e}$ & $2.06-14$ & $2 s^{2} 2 p^{3}{ }^{4} S^{o} 4 f$ & ${ }^{5} F^{e}$ & $3.52-15$ & $2 s^{2} 2 p^{3}{ }^{4} S^{o} 7 d$ & ${ }^{5} D^{o}$ & $4.87-15$ \\
\hline $2 s^{2} 2 p^{3}{ }^{4} S^{o} 6 f$ & ${ }^{5} F^{e}$ & $5.59-14$ & $2 s^{2} 2 p^{3}{ }^{4} S^{\circ} 4 p$ & ${ }^{5} P^{e}$ & $1.60-14$ & $2 s^{2} 2 p^{3}{ }^{4} S^{o} 5 f$ & ${ }^{5} F^{e}$ & $3.11-15$ & $2 s^{2} 2 p^{3}{ }^{4} S^{o} 8 d$ & ${ }^{5} D^{o}$ & $4.10-15$ \\
\hline Sum ................. & & $2.11-12$ & & & $6.51-13$ & & & $2.16-13$ & & & $1.63-13$ \\
\hline Total ................. & & $6.91-12$ & & & $1.48-12$ & & & $3.14-13$ & & & $1.89-12$ \\
\hline$\%$ Contribution....... & & 31 & & & 44 & & & 69 & & & 9 \\
\hline \multicolumn{12}{|c|}{$\mathrm{O}$ II $: g=\left(2 s^{2} 2 p^{3}\right)^{4} S^{o} ; N_{b}=292$} \\
\hline $2 s^{2} 2 p^{3}$ & ${ }^{4} S^{o}$ & $3.40-12$ & $2 s^{2} 2 p^{3}$ & ${ }^{2} D^{o}$ & $1.16-12$ & $2 s^{2} 2 p^{3}$ & ${ }^{2} D^{o}$ & $6.22-13$ & $2 s^{2} 2 p^{3}$ & ${ }^{2} D^{o}$ & $2.41-13$ \\
\hline $2 s^{2} 2 p^{3}$ & ${ }^{2} D^{o}$ & $3.00-12$ & $2 s^{2} 2 p^{3}$ & ${ }^{4} S^{o}$ & $1.08-12$ & $2 s^{2} 2 p^{3}$ & ${ }^{4} S^{o}$ & $3.68-13$ & $2 s^{2} 2 p^{3}$ & ${ }^{4} S^{o}$ & $1.89-13$ \\
\hline $2 s^{2} 2 p^{3}$ & ${ }^{2} P^{o}$ & $2.25-12$ & $2 s^{2} 2 p^{3}$ & ${ }^{2} P^{o}$ & $7.22-13$ & $2 s^{2} 2 p^{3}$ & ${ }^{2} P^{o}$ & $3.04-13$ & $2 s 2 p^{4}$ & ${ }^{4} P^{e}$ & $1.82-13$ \\
\hline $2 s^{2} 2 p 2^{3} P^{e} 3 d$ & ${ }^{4} F^{e}$ & $5.20-13$ & $2 s^{2} 2 p 2^{3} P^{e} 3 d$ & ${ }^{4} F^{e}$ & $1.62-13$ & $2 s 2 p^{4}$ & ${ }^{4} P^{e}$ & $5.55-14$ & $2 s^{2} 2 p^{3}$ & ${ }^{2} P^{o}$ & $1.39-13$ \\
\hline $2 s^{2} 2 p 2{ }^{3} P^{e} 3 d$ & ${ }^{4} D^{e}$ & $3.26-13$ & $2 s^{2} 2 p 2^{3} P^{e} 3 d$ & ${ }^{4} D^{e}$ & $1.02-13$ & $2 s^{2} 2 p 2^{3} P^{e} 3 d$ & ${ }^{4} F^{e}$ & $4.52-14$ & $2 s^{2} 2 p 2^{3} P^{e} 3 s$ & ${ }^{4} P^{e}$ & $3.81-14$ \\
\hline $2 s^{2} 2 p 2^{3} P^{e} 4 d$ & ${ }^{4} F^{e}$ & $2.99-13$ & $2 s^{2} 2 p 2^{3} P^{e} 4 d$ & ${ }^{4} F^{e}$ & $9.33-14$ & $2 s^{2} 2 p 2^{3} P^{e} 3 d$ & ${ }^{4} D^{e}$ & $2.81-14$ & $2 s 2 p^{4}$ & ${ }^{2} D^{e}$ & $3.59-14$ \\
\hline $2 s^{2} 2 p 2{ }^{3} P^{e} 3 p$ & ${ }^{4} D^{o}$ & $2.34-13$ & $2 s^{2} 2 p 2^{3} P^{e} 3 p$ & ${ }^{4} D^{o}$ & $7.50-14$ & $2 s^{2} 2 p 2^{3} P^{e} 3 p$ & ${ }^{4} D^{o}$ & $2.79-14$ & $2 s^{2} 2 p 2^{3} P^{e} 3 p$ & ${ }^{4} D^{o}$ & $3.43-14$ \\
\hline $2 s^{2} 2 p 2{ }^{3} P^{e} 3 d$ & ${ }^{2} F^{e}$ & $2.11-13$ & $2 s^{2} 2 p 2^{3} P^{e} 3 d$ & ${ }^{2} F^{e}$ & $6.56-14$ & $2 s^{2} 2 p 2^{3} P^{e} 4 d$ & ${ }^{4} F^{e}$ & $2.65-14$ & $2 s^{2} 2 p 2^{3} P^{e} 3 d$ & ${ }^{4} F^{e}$ & $3.39-14$ \\
\hline $2 s^{2} 2 p 2^{3} P^{e} 4 d$ & ${ }^{4} D^{e}$ & $1.98-13$ & $2 s^{2} 2 p 2^{3} P^{e} 4 d$ & ${ }^{4} D^{e}$ & $6.19-14$ & $2 s^{2} 2 p 2^{3} P^{e} 3 s$ & ${ }^{4} P^{e}$ & $2.65-14$ & $2 s^{2} 2 p 2^{3} P^{e} 4 f$ & ${ }^{4} D^{o}$ & $3.09-14$ \\
\hline $2 s^{2} 2 p 2{ }^{3} P^{e} 3 d$ & ${ }^{4} P^{e}$ & $1.74-13$ & $2 s^{2} 2 p 2^{3} P^{e} 3 d$ & ${ }^{4} P^{e}$ & $5.39-14$ & $2 s^{2} 2 p 2^{3} P^{e} 3 d$ & ${ }^{2} F^{e}$ & $1.80-14$ & $2 s^{2} 2 p 2^{3} P^{e} 6 g$ & ${ }^{4} H^{e}$ & $2.50-14$ \\
\hline Sum ................... & & $1.06-11$ & & & $3.57-12$ & & & $2.52-12$ & & & $9.49-13$ \\
\hline Total .................. & & $3.70-11$ & & & $9.06-12$ & & & $2.52-12$ & & & $5.59-12$ \\
\hline$\%$ Contribution...... & & 29 & & & 40 & & & 61 & & & 17 \\
\hline \multicolumn{12}{|c|}{$\mathrm{O}$ III: $g=\left(2 s^{2} 2 p^{2}\right)^{3} P^{e} ; N_{b}=284$} \\
\hline $2 s^{2} 2 p^{2}$ & ${ }^{3} P^{e}$ & $1.52-11$ & $2 s^{2} 2 p^{2}$ & ${ }^{3} P^{e}$ & $6.53-12$ & $2 s 2 p^{3}$ & ${ }^{3} D^{o}$ & $4.13-12$ & $2 s 2 p^{3}$ & ${ }^{3} D^{o}$ & $1.68-12$ \\
\hline $2 s 2 p^{3}$ & ${ }^{1} P^{o}$ & $1.28-11$ & $2 s^{2} 2 p^{2}$ & ${ }^{1} D^{e}$ & $2.00-12$ & $2 s^{2} 2 p^{2}$ & ${ }^{3} P^{e}$ & $1.56-12$ & $2 s^{2} 2 p^{2}$ & ${ }^{3} P^{e}$ & $7.17-13$ \\
\hline $2 s^{2} 2 p^{2} P^{o} 3 s$ & ${ }^{1} P^{o}$ & $7.12-12$ & $2 s 2 p^{3}$ & ${ }^{1} P^{o}$ & $1.74-12$ & $2 s 2 p^{3}$ & ${ }^{3} P^{o}$ & $9.41-13$ & $2 s 2 p^{3}$ & ${ }^{3} P^{o}$ & $5.61-13$ \\
\hline $2 s^{2} 2 p^{2}$ & ${ }^{1} D^{e}$ & $6.28-12$ & $2 s^{2} 2 p^{2} P^{o} 3 s$ & ${ }^{1} P^{o}$ & $1.10-12$ & $2 s^{2} 2 p^{2}$ & ${ }^{1} D^{e}$ & $6.60-13$ & $2 s^{2} 2 p^{2}$ & ${ }^{1} D^{e}$ & $3.40-13$ \\
\hline $2 s 2 p^{3}$ & ${ }^{3} D^{o}$ & $1.88-12$ & $2 s 2 p^{3}$ & ${ }^{3} D^{o}$ & $6.72-13$ & $2 s^{2} 2 p^{2} P^{o} 3 s$ & ${ }^{3} P^{o}$ & $4.65-13$ & $2 s 2 p^{3}$ & ${ }^{1} D^{o}$ & $3.36-13$ \\
\hline $2 s^{2} 2 p^{2} P^{o} 3 p$ & ${ }^{3} D^{e}$ & $1.69-12$ & $2 s^{2} 2 p^{2} P^{o} 3 p$ & ${ }^{3} S^{e}$ & $6.01-13$ & $2 s 2 p^{3}$ & ${ }^{1} D^{o}$ & $4.54-13$ & $2 s^{2} 2 p^{2} P^{o} 3 p$ & ${ }^{3} D^{e}$ & $2.29-13$ \\
\hline $2 s^{2} 2 p^{2}$ & ${ }^{1} S^{e}$ & $1.59-12$ & $2 s^{2} 2 p^{2} P^{o} 3 p$ & ${ }^{3} D^{e}$ & $5.16-13$ & $2 s^{2} 2 p^{2} P^{o} 3 d$ & ${ }^{3} F^{o}$ & $3.14-13$ & $2 s^{2} 2 p^{2} P^{o} 3 d$ & ${ }^{3} F^{o}$ & $2.28-13$ \\
\hline $2 s^{2} 2 p^{2} P^{o} 3 p$ & ${ }^{3} S^{e}$ & $1.38-12$ & $2 s^{2} 2 p^{2}$ & ${ }^{1} S^{e}$ & $5.05-13$ & $2 s^{2} 2 p^{2} P^{o} 3 p$ & ${ }^{3} D^{e}$ & $2.31-13$ & $2 s^{2} 2 p^{2} P^{o} 3 s$ & ${ }^{3} P^{o}$ & $1.82-13$ \\
\hline $2 s^{2} 2 p^{2} P^{o} 3 p$ & ${ }^{3} P^{e}$ & $1.05-12$ & $2 s^{2} 2 p^{2} P^{o} 3 p$ & ${ }^{3} P^{e}$ & $3.24-13$ & $2 s^{2} 2 p^{2} P^{o} 3 d$ & ${ }^{3} D^{o}$ & $2.23-13$ & $2 s 2 p^{3}$ & ${ }^{1} P^{o}$ & $1.47-13$ \\
\hline $2 s^{2} 2 p^{2} P^{o} 3 d$ & ${ }^{3} F^{o}$ & $1.02-12$ & $2 s^{2} 2 p^{2} P^{o} 3 d$ & ${ }^{3} F^{o}$ & $3.10-13$ & $2 s 2 p^{3}$ & ${ }^{1} P^{o}$ & $2.00-13$ & $2 s^{2} 2 p^{2} P^{o} 3 d$ & ${ }^{3} D^{o}$ & $1.22-13$ \\
\hline Sum ................. & & $5.00-11$ & & & $1.43-11$ & & & $9.18-12$ & & & $4.55-12$ \\
\hline Total ................. & & $1.23-10$ & & & $3.15-11$ & & & $1.33-11$ & & & $1.56-11$ \\
\hline$\%$ Contribution....... & & 41 & & & 45 & & & 69 & & & 29 \\
\hline
\end{tabular}

(Yan \& Seaton 1987) that are usually much wider and more enhanced than the Rydberg resonances. The PEC resonances occur at an excited target state accessible from the target ground state via a dipole allowed transition. For example, during the photoionization of $\mathrm{O}$ II, the target $\mathrm{O}$ III ground state, $2 s^{2} 2 p^{2}\left({ }^{3} P\right)$, can be excited to states such as, $2 s 2 p^{3}\left({ }^{3} D^{o},{ }^{3} P^{o},{ }^{3} S^{o}\right)$, and $2 s^{2} 2 p 3 s\left({ }^{3} P^{o}\right)$, through dipole allowed transitions. These transitions would introduce PEC resonances in photoionization of excited states of $\mathrm{O}$ II. Examples are shown in Figure 2, where values of $\sigma_{\mathrm{PI}}$ of a series of excited states, $2 s^{2} 2 p^{2} n d\left({ }^{4} F\right)$, where $10 d \leq n d \leq 3 d$, are presented. The PEC resonances are clearly evident in the cross sections, where their positions are marked by the arrows in the lowest panel. The background cross sections are also enhanced considerably by the PEC resonances, an important contributing factor in the recombination process at higher temperatures. The PEC resonances are more prominent in the photoionization of excited Rydberg states where the outer electron is weakly coupled to the ion core (i.e., a "spectator").

The DR collision strengths, $\Omega(\mathrm{DR})$, of the high- $n$ states are obtained as in Nahar (1996b) and using the code STGFDR. Resonances that decay to the ground state of the target ion are considered. The radiative transition probabil- 
TABLE $1-$ Continued

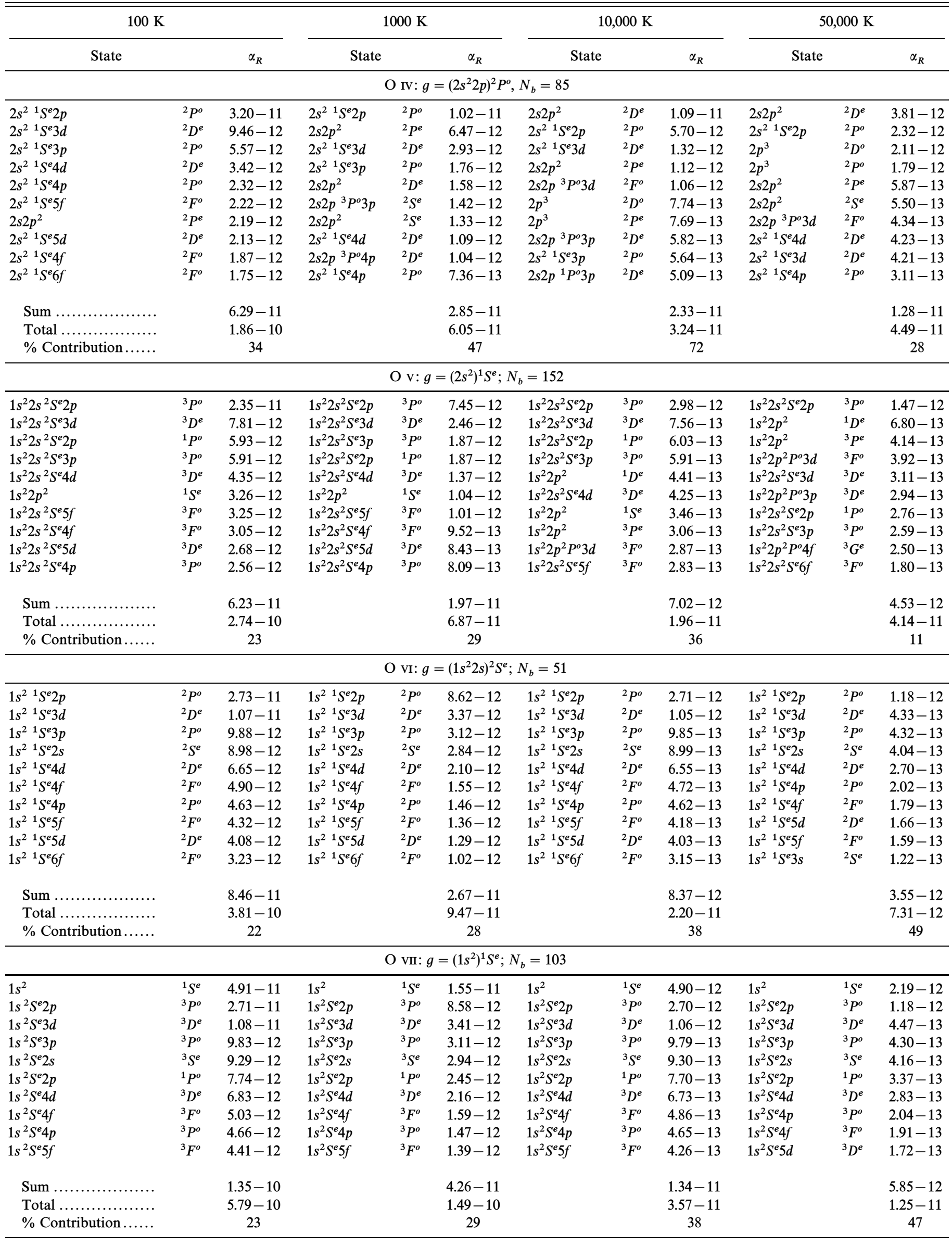

${ }^{a}$ Coefficients are given (in units of $\mathrm{cm}^{3} \mathrm{~s}^{-1}$ ) for the 10 most contributing states for each oxygen ion at temperatures $T=100,1000,10,000$, and $50,000 \mathrm{~K}$, listed in the order of the percentage of their contributions to the total $\alpha_{R}$. In the main heading for each ion, $g$ is the ground state of the ion and $N_{b}$ is the total number of low- $n$ bound states whose state-specific rates are added to the total $\alpha_{R}$. 


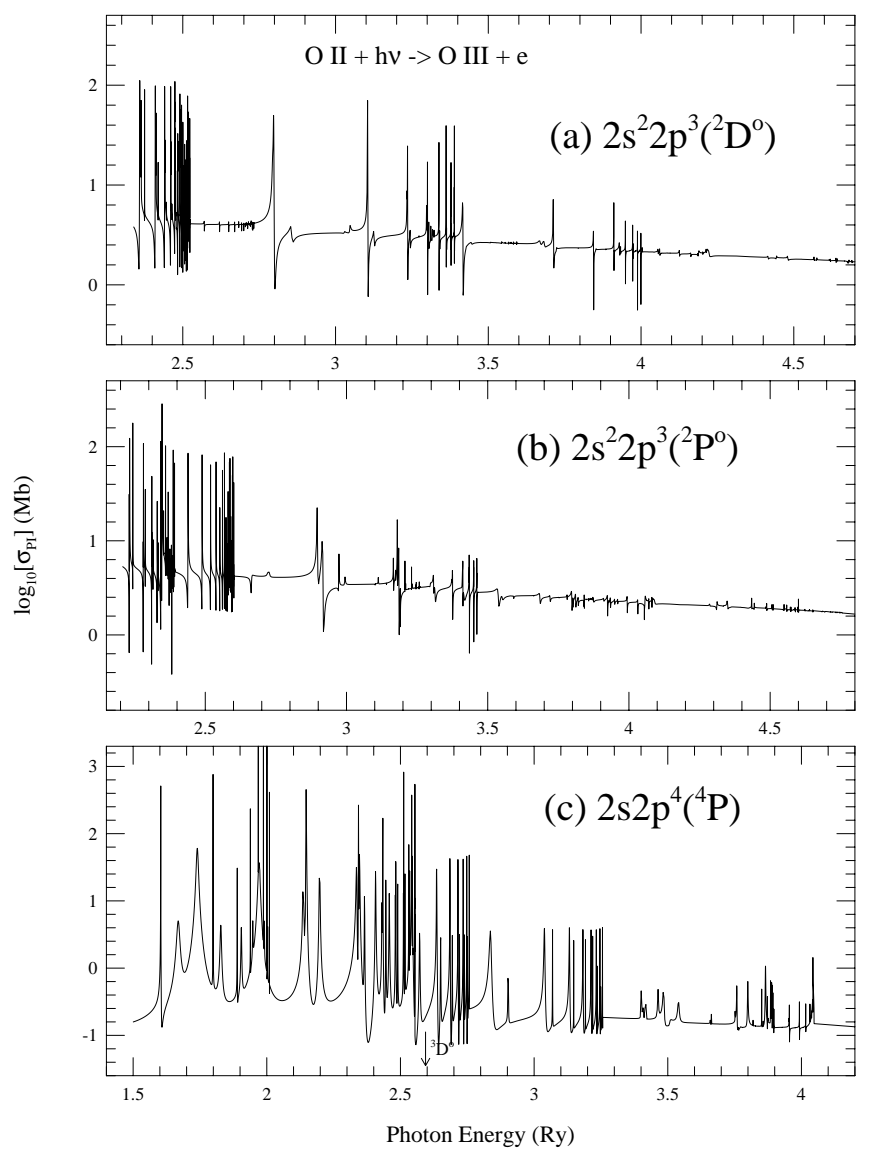

FIG. 1.-Partial photoionization cross sections, $\sigma_{\mathrm{PI}}$, of the excited states of O II: (a) $2 s^{2} 2 p^{3}\left({ }^{2} D^{o}\right),(b) 2 s^{2} 2 p^{3}\left({ }^{2} P^{o}\right)$, and $(c) 2 s 2 p^{4}\left({ }^{4} P\right)$, dominant contributors to the total $\alpha_{R}(T)$.

ities ( $A$-values given in Table 2$)$ for the dipole allowed transitions to the target ground state for each ion are obtained from the $f$-values (Nahar 1998) computed using the same eigenfunction expansion as for the $\sigma_{\mathrm{PI}}$. Both forms of $\Omega(\mathrm{DR})$, including detailed resonance profiles, and the resonance averaged, are obtained.

An example of the DR collision strengths, $\Omega(\mathrm{DR})$, is presented in Figure 3 for $(e+\mathrm{O}$ III $) \rightarrow \mathrm{O}$ II. The lower panel shows $\Omega$ (DR) below the four O III thresholds, ${ }^{3} D^{o},{ }^{3} P^{o},{ }^{3} S^{o}$, and ${ }^{3} P^{o}$. The resonance structures belonging to the two $\mathrm{O}$ III thresholds, ${ }^{3} D^{o}$ and ${ }^{3} P^{o}$, in the lower panel are expanded in the upper panel of the figure. The dotted curve shows the detailed resonances, and the solid curve shows the resonance averaged form of $\Omega(D R)$. Typical features are exhibited in the figures. The narrow resonances become denser as the effective quantum number increases below the converging threshold (indicated by an arrow). The rise in the background indicates that the DR process increases sharply as the energy approaches the threshold. Beyond the threshold, DR goes to zero as the electron flux trapped in the resonances below the threshold, due to radiative decay of the core, is released through excitation of the given target state. It may be noted from the resonance-averaged $\Omega(D R)$ (solid curve) that radiation damping of resonances below $v=10.0$, where computation of $\Omega(\mathrm{DR})$ begins, is negligible. DR rate coefficients are obtained from $\Omega(D R)$ through Maxwellian averaging at different temperatures, and are added as the high- $n$ contributions to the total rate. Rates computed from the resonance-averaged $\langle\Omega(D R)\rangle$, rather than the detailed $\Omega(\mathrm{DR})$, are added to the total recombination rate, since they are computed accurately using an analytic expression (NP2; Nahar 1996b).

In Figure 3 the filled circles are the electron impact excitation (EIE) collision strength, $\Omega_{\mathrm{EIE}}$, at the thresholds for excitation of the ground state. We carry out independent $\mathrm{CC}$ electron-ion scattering calculations for EIE collision strengths, $\Omega$ (EIE), at the excited target thresholds. The same wave function is used as employed for DR and photoionization, i.e., $\Omega(\mathrm{DR})$ and $\sigma_{\mathrm{PI}}$. Values of $\Omega(\mathrm{EIE})$ are obtained by including and excluding the multipole potentials to determine the effect of these potentials on $\Omega(D R)$, since the DR theory by Bell \& Seaton (1985) does not include them. However, the differences can be compensated via a proper choice of $\boldsymbol{R}$-matrix boundary and the basis set (NP2). Table 2 presents these $\Omega$ (EIE) values for the oxygen ions where generally good agreement can be found between the two sets. This indicates that the contributions of multipole potentials are not significant in the present calculations. $\Omega($ EIE) excluding the multipole potentials are compared with the resonance-averaged DR collision strength, $\langle\Omega(\mathrm{DR})\rangle$, at the thresholds in Table 2 and in Figure 3 to check for conservation of total flux of electrons and photons in the DR process. The flux trapped below a target threshold due to DR should be equal to that released by excitation at the same threshold, i.e., $\Omega(D R)$ should match $\Omega$ (EIE). Good agreement between the two sets of collision strengths is seen in Table 2. Note that in the case of target states that have degenerate energies, such as the $2 s 2 p 3 p\left({ }^{2} D, P^{2}, S^{2}\right)$ states of the $\mathrm{O}$ IV target, the sum of $\Omega$ (EIE) for these states should correspond to the peak value of $\Omega(\mathrm{DR})$ at the degenerate threshold, and we find good agreement between the two values, 0.193 and 0.198 .

Present computations are carried out in $L S$ coupling for all ions. However, the computations for $\mathrm{O}$ vII are repeated to include the relativistic fine-structure effects, since they may be important for this comparatively highly charged ion. In addition, the resonances could be damped through a second-order radiation damping effect. Although typical autoionization rates are high for the lowest resonances near the ionization threshold, $A_{a} \sim 10^{14}-10^{15} \mathrm{~s}^{-1}$, these decrease as $v^{-3}$, where $v$ is the effective quantum number relative to the ion excited state. The radiative transition probabilities for the $\mathrm{O}$ VIII target are of the order of $10^{12} \mathrm{~s}^{-1}$ ( $A$-values in atomic units in Table 2 divided by the atomic unit of time $2.419 \times 10^{-17} \mathrm{~s}$ ), a few orders of magnitude lower than the autoionization rates. Therefore, some effect of the second-order radiation damping is expected for $v \leq 10$. The Breit-Pauli (BP) photorecombination cross sections are calculated allowing for radiation damping of resonances in the photoionization cross sections (Zhang, Nahar, \& Pradhan 1998). Contributions from resonances with $10<v \leq \infty$ are treated precisely through a computational formalism based on the Bell \& Seaton (1985) theory of DR (Pradhan \& Zhang 1997).

The recombination rate coefficients for the hydrogenic ion, O VIII, are obtained from $\alpha_{R}(T)$ values for neutral hydrogen applying the $z$-scale formula $\alpha_{R}(z, T)=$ $\alpha_{R}\left(1, T / z^{2}\right)$, where $z$ is the ion charge (Nahar $1996 \mathrm{~b}$ ).

The total recombination rates $\alpha_{R}(T)$, calculated for all $\mathrm{O}$ ions in this work, are used to obtain ionization fractions in coronal equilibrium corresponding to plasmas ionized by electron impact ionization (rather than photoionization as in radiatively ionized sources). The relative concentrations 


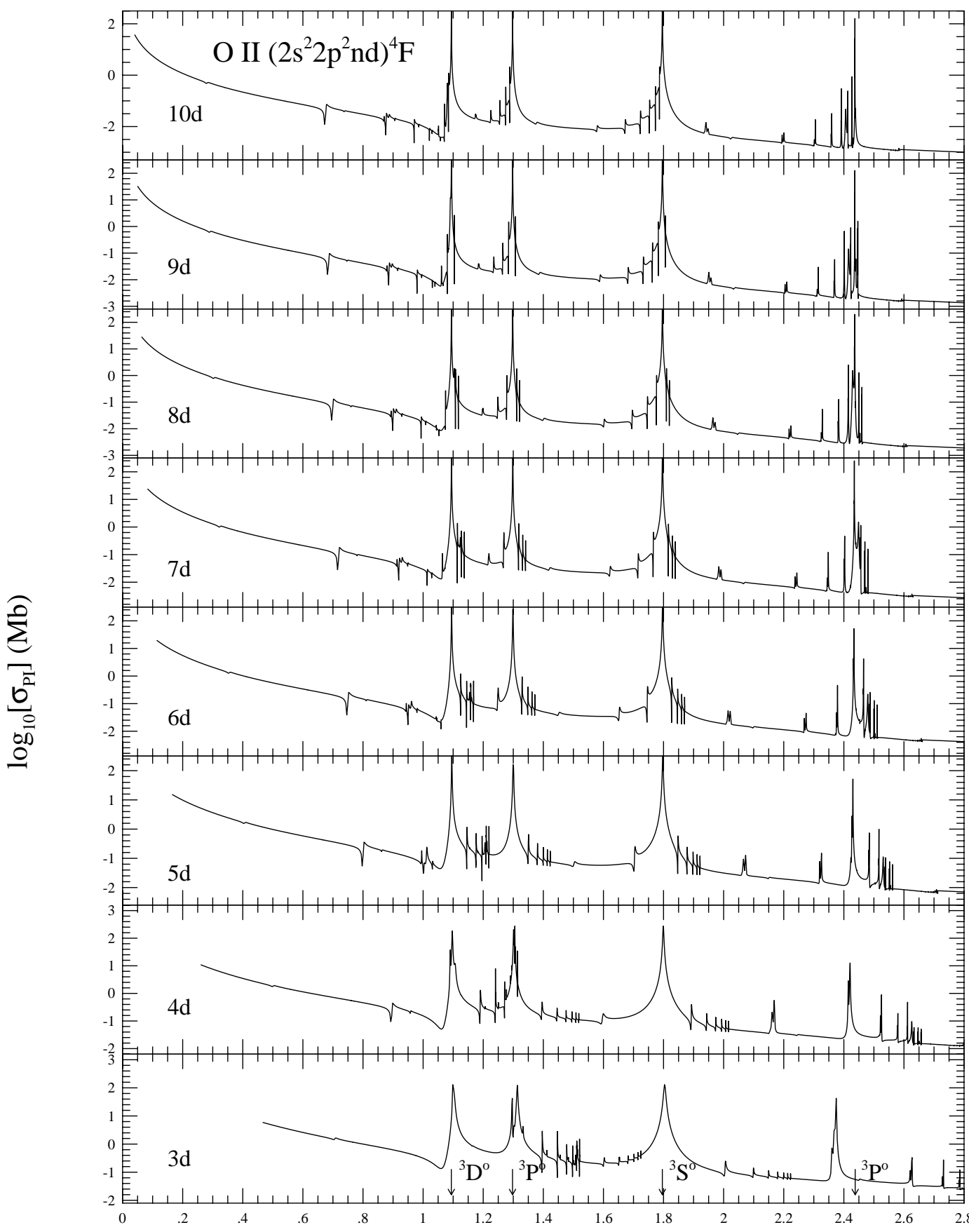

Photon Energy (Ry)

Fig. 2.-Partial photoionization cross sections of the Rydberg series of bound states, $2 s^{2} 2 p^{2} n d\left({ }^{4} F\right), 3 d \leq n d \leq 10 d$, of $\mathrm{O}$ in illustrating the photoexcitation of core (PEC) resonances (indicated by arrows in the lowest panel) corresponding to dipole allowed transitions by the target ground state, ${ }^{3} P$.

of ions of a given element in coronal equilibrium are determined by the coupled ionization equations as

$$
N(z-1, g) S(z-1, g)=N(z, g) \alpha(z, g), \quad 1 \leq z \leq z_{\max },
$$

together with the normalization condition

$$
N_{T}=\sum_{z=0}^{z_{\max }} N(z, g),
$$

where $N(z-1)$ and $N(z)$ are the densities for the recombining and recombined ions, respectively, and $S(z-1, g)$ is the total rate coefficient for electron impact ionization from the ground state of the ion $X(z-1)$. The $\alpha(z, g)$ is the total recombination rate coefficient as computed herein. The recombining ion is assumed to be in the ground state, since the dominant stabilizing radiative transitions are to the ground state. The values of $S$ for electron impact ionization for oxygen ions are taken from the latest compilation of experimental and theoretical data assessed by Bell et al. 
TABLE 2

Transition Probabilities and Collision Strengths for Target Ground State to Excited State Dipole Allowed Transitions ${ }^{\mathrm{a}}$

\begin{tabular}{|c|c|c|c|c|}
\hline \multirow[b]{2}{*}{ Transition } & \multirow{2}{*}{$\begin{array}{r}A_{\mathrm{fi}} \\
\text { (a.u.) }\end{array}$} & \multicolumn{2}{|c|}{$\Omega(\mathrm{EIE})$} & \multirow[b]{2}{*}{$\langle\Omega(\mathrm{DR})\rangle$} \\
\hline & & $\mathrm{mp} 0$ & $\mathrm{mp} 1$ & \\
\hline \multicolumn{5}{|c|}{ O II: $8-\mathrm{CC}$} \\
\hline $2 s^{2} 2 p^{3}\left({ }^{4} S^{o}\right) \rightarrow 2 s 2 p^{4}\left({ }^{4} P\right)$. & $2.09 \mathrm{E}-08$ & 3.06 & 3.14 & 3.05 \\
\hline $2 s^{2} 2 p^{3}\left({ }^{4} S^{o}\right) \rightarrow 2 s^{2} 2 p^{2} 3 s\left({ }^{4} P\right) \ldots \ldots$ & $2.35 \mathrm{E}-08$ & 1.96 & 1.95 & 2.10 \\
\hline \multicolumn{5}{|c|}{ O III: $12-\mathrm{CC}$} \\
\hline $2 s^{2} 2 p^{2}\left({ }^{3} P\right) \rightarrow 2 s 2 p^{3}\left({ }^{3} D^{o}\right) \ldots$ & $1.54 \mathrm{E}-08$ & 5.34 & 5.57 & 5.35 \\
\hline $2 s^{2} 2 p^{2}\left({ }^{3} P\right) \rightarrow 2 s 2 p^{3}\left({ }^{3} P^{o}\right) \ldots \ldots \ldots$ & $5.00 \mathrm{E}-08$ & 4.28 & 4.36 & 4.28 \\
\hline $2 s^{2} 2 p^{2}\left({ }^{3} P\right) \rightarrow 2 s 2 p^{3}\left({ }^{3} S^{o}\right) \ldots \ldots \ldots$ & $3.80 \mathrm{E}-07$ & 3.62 & 3.50 & 3.62 \\
\hline $2 s^{2} 2 p^{2}\left({ }^{3} P\right) \rightarrow 2 s^{2} 2 p 3 s\left({ }^{3} P^{o}\right) \ldots \ldots$ & $9.24 \mathrm{E}-08$ & 0.799 & 0.819 & 0.805 \\
\hline \multicolumn{5}{|c|}{ O IV: $23-\mathrm{CC}$} \\
\hline $2 s^{2} 2 p\left({ }^{2} P^{o}\right) \rightarrow 2 s 2 p^{2}\left({ }^{2} D\right)$. & $1.74 \mathrm{E}-08$ & 6.22 & 5.37 & 6.25 \\
\hline $2 s^{2} 2 p\left({ }^{2} P^{o}\right) \rightarrow 2 s 2 p^{2}\left({ }^{2} S\right) \ldots \ldots \ldots \ldots$ & $9.08 \mathrm{E}-08$ & 2.66 & 2.32 & 2.66 \\
\hline $2 s^{2} 2 p\left({ }^{2} P^{o}\right) \rightarrow 2 s 2 p^{2}\left({ }^{2} P\right) \ldots \ldots \ldots \ldots$ & $1.81 \mathrm{E}-07$ & 8.68 & 7.72 & 8.90 \\
\hline $2 s^{2} 2 p\left({ }^{2} P^{o}\right) \rightarrow 2 s^{2} 3 s\left({ }^{2} S\right) \ldots \ldots \ldots \ldots$ & $1.93 \mathrm{E}-07$ & 0.533 & 0.705 & 0.534 \\
\hline $2 s^{2} 2 p\left({ }^{2} P^{o}\right) \rightarrow 2 s^{2} 3 d\left({ }^{2} D\right) \ldots$ & $8.53 \mathrm{E}-07$ & 2.26 & 2.30 & 2.28 \\
\hline $2 s^{2} 2 p\left({ }^{2} P^{o}\right) \rightarrow 2 s 2 p 3 p\left({ }^{2} P\right) .$. & $2.63 \mathrm{E}-07$ & 0.132 & 0.105 & 0.132 \\
\hline $2 s^{2} 2 p\left({ }^{2} P^{o}\right) \rightarrow 2 s 2 p 3 p\left({ }^{2} D\right) \ldots$ & $2.83 \mathrm{E}-07$ & 0.311 & 0.278 & 0.376 \\
\hline $2 s^{2} 2 p\left({ }^{2} P^{o}\right) \rightarrow 2 s 2 p 3 p\left({ }^{2} S\right) \ldots \ldots \ldots$ & $2.57 \mathrm{E}-07$ & 0.366 & 0.343 & 0.366 \\
\hline $2 s^{2} 2 p\left({ }^{2} P^{o}\right) \rightarrow 2 s 2 p 3 p\left({ }^{2} D\right) \ldots \ldots \ldots$ & $5.08 \mathrm{E}-08$ & 0.0618 & 0.0573 & $\downarrow$ \\
\hline $2 s^{2} 2 p\left({ }^{2} P^{o}\right) \rightarrow 2 s 2 p 3 p\left({ }^{2} P\right) \ldots \ldots \ldots$ & $7.63 \mathrm{E}-08$ & 0.0998 & 0.097 & $\downarrow$ \\
\hline $2 s^{2} 2 p\left({ }^{2} P^{o}\right) \rightarrow 2 s 2 p 3 p\left({ }^{2} S\right) \ldots \ldots \ldots$ & $1.03 \mathrm{E}-07$ & 0.0317 & 0.0287 & $\downarrow$ \\
\hline & & 0.193 (sum) & 0.183 (sum) & 0.198 \\
\hline \multicolumn{5}{|c|}{$\mathrm{O}$ v: $12-\mathrm{CC}$} \\
\hline $2 s^{2}\left({ }^{1} S\right) \rightarrow 2 s 2 p\left({ }^{1} P^{o}\right)$. & $4.12 \mathrm{E}-07$ & 2.93 & 3.06 & 2.93 \\
\hline $2 s^{2}\left({ }^{1} S\right) \rightarrow 2 s 3 p\left({ }^{1} P^{o}\right) \ldots \ldots \ldots \ldots \ldots$ & $2.10 \mathrm{E}-08$ & 0.0638 & 0.0594 & 0.0664 \\
\hline \multicolumn{5}{|c|}{$\mathrm{O}$ VI: $9-\mathrm{CC}$} \\
\hline $1 s^{2} 2 s\left({ }^{2} S\right) \rightarrow 1 s^{2} 2 p\left({ }^{2} P^{o}\right) \ldots \ldots \ldots \ldots$ & $9.89 \mathrm{E}-09$ & 5.38 & 5.09 & 5.37 \\
\hline $1 s^{2} 2 s\left({ }^{2} S\right) \rightarrow 1 s^{2} 3 p\left({ }^{2} P^{o}\right) \ldots \ldots \ldots \ldots$ & $6.32 \mathrm{E}-07$ & 0.318 & 0.318 & 0.392 \\
\hline $1 s^{2} 2 s\left({ }^{2} S\right) \rightarrow 1 s^{2} 4 p\left({ }^{2} P^{o}\right) \ldots \ldots \ldots \ldots$ & $2.96 \mathrm{E}-07$ & 0.0454 & 0.0454 & 0.0545 \\
\hline \multicolumn{5}{|c|}{ O vII: $11-\mathrm{CC}$} \\
\hline $1 s^{2}\left({ }^{1} S\right) \rightarrow 1 s 2 p\left({ }^{1} P^{o}\right) \ldots \ldots .$. & $7.97 \mathrm{E}-05$ & 0.0184 & 0.0186 & 0.0184 \\
\hline $1 s^{2}\left({ }^{1} S\right) \rightarrow 1 s 2 p\left({ }^{1} P^{o}\right) \ldots \ldots \ldots \ldots \ldots$ & $2.26 \mathrm{E}-05$ & 0.0046 & 0.0043 & 0.046 \\
\hline \multicolumn{5}{|c|}{ O VIII: $10-\mathrm{CC}$} \\
\hline $1 s\left({ }^{2} S\right) \rightarrow 2 p\left({ }^{2} P^{o}\right) \ldots \ldots \ldots \ldots \ldots \ldots$ & $6.21 \mathrm{E}-05$ & 0.0423 & 0.0423 & 0.0424 \\
\hline $1 s\left({ }^{2} S\right) \rightarrow 3 p\left({ }^{2} P^{o}\right) \ldots \ldots \ldots \ldots$ & $1.66 \mathrm{E}-05$ & 0.0090 & 0.0090 & 0.0090 \\
\hline $1 s\left({ }^{2} S\right) \rightarrow 4 p\left({ }^{2} P^{o}\right) \ldots \ldots \ldots \ldots$ & $6.76 \mathrm{E}-06$ & 0.0011 & 0.0011 & 0.0012 \\
\hline
\end{tabular}

${ }^{\text {a }}$ Transition probabilities ( $A$-values) of the target ground state to excited states via dipoleallowed transitions; excitation collision strengths, $\Omega$ (EIE), at these excited thresholds for the same transitions, excluding (mp0) and including (mp1) the contributions of the multipole potentials; and the peak values of DR collision strengths, $\langle\Omega(\mathrm{DR})\rangle$ at the same excited thresholds. $\Omega$ (EIE) with $\mathrm{mp} 0$ is compared with $\langle\Omega(\mathrm{DR})\rangle$ at these thresholds. The downwardpointing arrows in the far-right column indicate the net total given below. The wave function size for each ion is specified in the main heading for the relevant section.

(1983), who provide fitting formulae based on recommended data.

The ionization balance equation in photoionization equilibrium may be written as

$$
\int_{v_{0}}^{\infty} \frac{4 \pi J_{v}}{h v} N(z-1) \sigma_{\mathrm{PI}}[v, X(z)] d v=N_{e} N(z) \alpha_{R}(z ; T),
$$

where $\sigma_{\mathrm{PI}}$ is the photoionization cross section evaluated at photon frequency $v$, and convoluted by an isotropic radi- ation density $J_{v}$ of the source; $N_{e}$ is the density for the free electrons. These ionization fractions can be evaluated using the present total recombination rate coefficients and photoionization cross sections in Nahar (1998).

\section{RESULTS AND DISCUSSION}

The sets of computed parameters, total and partial recombination rates, and photoionization cross sections, are discussed in the subsections below. 

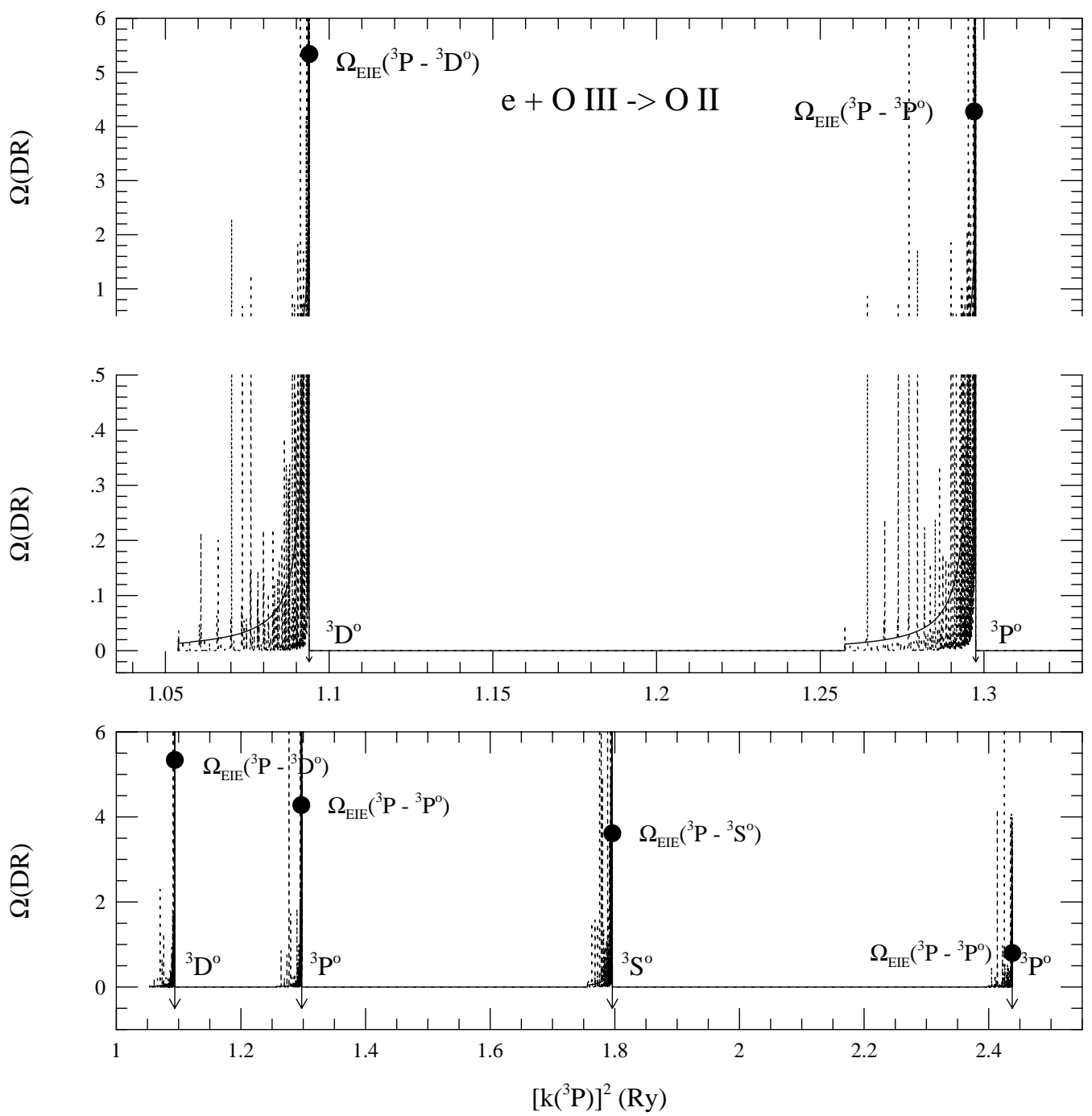

FIG. 3.-DR collision strengths, $\Omega(\mathrm{DR})$, for $e+\mathrm{O} \mathrm{III} \rightarrow \mathrm{O} \mathrm{II}:$ detailed with resonances (dotted curve) and averaged over resonances (solid curve) in the regions below and at the excited thresholds for dipole allowed transitions from the target ground state. The filled circles are the electron-impact excitation collision strengths, $\Omega_{\mathrm{EIE}}$, at the thresholds. The upper panel gives the extended view of $\Omega(\mathrm{DR})$ below the first two thresholds.

\subsection{State-specific and Total Recombination Rate Coefficients}

The state-specific recombination rates are needed for various astrophysical calculations, such as determination of level populations, recombination rates for lines, etc. These rates are obtained for all group A bound states of each oxygen ion. The state-specfic, partial recombination rate coefficients of the first 10 most dominant states are listed in Table 1 at four temperatures, 100,1000,10,000, and 50,000 $\mathrm{K}$. They are ordered in terms of their percentage contributions to the total $\alpha_{R}(T)$ at these temperatures. The ground state, specified in Table 1 in the main heading for each ion, may not necessarily be the dominant contributor at all temperatures. The order and the amount of the contributions of the individual bound states vary with temperature, depending on the positions of autoionizing resonances in the photoionization cross sections. The percentage contributions of the states indicate that a limited number of states usually dominate the recombination rates. It may be noted that the individual, state-specific, recombination rates of the low- $n$ bound states of group A are the total recombination rate coefficients for these states at the temperatures given, since the incident electron energies lie well below the excited target threshold for the DR process of high- $n$ states to become significant. The high- $n$ DR contributions are not included in the state-specific recombination rates, and therefore these may be less reliable at higher temperatures.

The total recombination rate coefficients for all oxygen ions, $\mathrm{O}$ I-O VIII, are presented for a wide range of temperatures for all astrophysical applications. The numerical values are given in Table 3 with a temperature mesh of $\log _{10}$ $T=0.1 \mathrm{~K}$ for easy interpolation. Present values, obtained in a self-consistent manner using a unified treatment, should be of higher accuracy than the currently available RR and DR rates calculated in several different approximations of varying reliability. However, uncertainties may be larger at very high temperatures where the cross sections are extrapolated. The temperature, $T_{0}$, beyond which extrapolation begins for each ion is specified in the column head of Table 3.

The characteristic feature of the total recombination rate $\alpha_{R}(T)$, as established in our earlier works (e.g., NP1), is that it starts with high values at low temperatures and decreases until it reaches a minimum. Thereafter, the $\alpha_{R}(T)$ rises as a 
TABLE 3

Total Recombination Rate CoEFficients fOR O I-O viII ${ }^{\mathrm{a}}$

\begin{tabular}{|c|c|c|c|c|c|c|c|c|}
\hline \multirow[b]{2}{*}{$\log _{10} T$} & \multicolumn{8}{|c|}{$\alpha_{R}(T)$} \\
\hline & $\begin{array}{l}\mathrm{O}_{\mathrm{I}} \\
5.4\end{array}$ & $\begin{array}{c}\text { O II } \\
5.6\end{array}$ & $\begin{array}{c}\text { O III } \\
5.9\end{array}$ & $\begin{array}{c}\text { O IV } \\
5.9\end{array}$ & $\begin{array}{c}\mathrm{O} v \\
6.1\end{array}$ & $\begin{array}{c}\text { O VI } \\
6.9\end{array}$ & $\begin{array}{c}\text { O VII } \\
7.0\end{array}$ & O vIII \\
\hline $1.0 \ldots \ldots$ & $2.91 \mathrm{E}-11$ & $1.45 \mathrm{E}-10$ & $4.49 \mathrm{E}-10$ & $6.91 \mathrm{E}-10$ & $1.02 \mathrm{E}-09$ & $1.41 \mathrm{E}-09$ & $2.11 \mathrm{E}-09$ & $2.90 \mathrm{E}-09$ \\
\hline $1.1 .$. & $2.53 \mathrm{E}-11$ & $1.27 \mathrm{E}-10$ & $3.96 \mathrm{E}-10$ & $6.08 \mathrm{E}-10$ & $9.01 \mathrm{E}-10$ & $1.25 \mathrm{E}-09$ & $1.86 \mathrm{E}-09$ & $2.56 \mathrm{E}-09$ \\
\hline $1.2 \ldots$ & $2.20 \mathrm{E}-11$ & $1.11 \mathrm{E}-10$ & $3.48 \mathrm{E}-10$ & $5.35 \mathrm{E}-10$ & $7.91 \mathrm{E}-10$ & $1.10 \mathrm{E}-09$ & $1.64 \mathrm{E}-09$ & $2.26 \mathrm{E}-09$ \\
\hline $1.3 \ldots \ldots$ & $1.91 \mathrm{E}-11$ & $9.71 \mathrm{E}-11$ & $3.06 \mathrm{E}-10$ & $4.69 \mathrm{E}-10$ & $6.95 \mathrm{E}-10$ & $9.63 \mathrm{E}-10$ & $1.44 \mathrm{E}-09$ & $2.00 \mathrm{E}-09$ \\
\hline $1.4 \ldots \ldots$ & $1.65 \mathrm{E}-11$ & $8.48 \mathrm{E}-11$ & $2.69 \mathrm{E}-10$ & $4.12 \mathrm{E}-10$ & $6.11 \mathrm{E}-10$ & $8.45 \mathrm{E}-10$ & $1.27 \mathrm{E}-09$ & $1.76 \mathrm{E}-09$ \\
\hline $1.5 \ldots \ldots$ & $1.43 \mathrm{E}-11$ & $7.39 \mathrm{E}-11$ & $2.37 \mathrm{E}-10$ & $3.61 \mathrm{E}-10$ & $5.36 \mathrm{E}-10$ & $7.42 \mathrm{E}-10$ & $1.12 \mathrm{E}-09$ & $1.55 \mathrm{E}-09$ \\
\hline $1.6 \ldots \ldots$ & $1.24 \mathrm{E}-11$ & $6.45 \mathrm{E}-11$ & $2.08 \mathrm{E}-10$ & $3.16 \mathrm{E}-10$ & $4.69 \mathrm{E}-10$ & $6.50 \mathrm{E}-10$ & $9.80 \mathrm{E}-10$ & $1.36 \mathrm{E}-09$ \\
\hline $1.7 \ldots \ldots$ & $1.07 \mathrm{E}-11$ & $5.62 \mathrm{E}-11$ & $1.83 \mathrm{E}-10$ & $2.77 \mathrm{E}-10$ & $4.11 \mathrm{E}-10$ & $5.69 \mathrm{E}-10$ & $8.60 \mathrm{E}-10$ & $1.20 \mathrm{E}-09$ \\
\hline $1.8 \ldots$ & $9.28 \mathrm{E}-12$ & $4.88 \mathrm{E}-11$ & $1.60 \mathrm{E}-10$ & $2.43 \mathrm{E}-10$ & $3.59 \mathrm{E}-10$ & $4.99 \mathrm{E}-10$ & $7.55 \mathrm{E}-10$ & $1.05 \mathrm{E}-09$ \\
\hline $1.9 \ldots$ & $8.01 \mathrm{E}-12$ & $4.26 \mathrm{E}-11$ & $1.41 \mathrm{E}-10$ & $2.13 \mathrm{E}-10$ & $3.14 \mathrm{E}-10$ & $4.36 \mathrm{E}-10$ & $6.61 \mathrm{E}-10$ & $9.26 \mathrm{E}-10$ \\
\hline $2.0 \ldots$ & $6.91 \mathrm{E}-12$ & $3.70 \mathrm{E}-11$ & $1.23 \mathrm{E}-10$ & $1.86 \mathrm{E}-10$ & $2.74 \mathrm{E}-10$ & $3.81 \mathrm{E}-10$ & $5.79 \mathrm{E}-10$ & $8.12 \mathrm{E}-10$ \\
\hline $2.1 \ldots$ & $5.96 \mathrm{E}-12$ & $3.21 \mathrm{E}-11$ & $1.08 \mathrm{E}-10$ & $1.63 \mathrm{E}-10$ & $2.40 \mathrm{E}-10$ & $3.32 \mathrm{E}-10$ & $5.07 \mathrm{E}-10$ & $7.12 \mathrm{E}-10$ \\
\hline $2.2 \ldots$ & $5.12 \mathrm{E}-12$ & $2.79 \mathrm{E}-11$ & $9.49 \mathrm{E}-11$ & $1.42 \mathrm{E}-10$ & $2.09 \mathrm{E}-10$ & $2.90 \mathrm{E}-10$ & $4.44 \mathrm{E}-10$ & $6.23 \mathrm{E}-10$ \\
\hline $2.3 \ldots$ & $4.41 \mathrm{E}-12$ & $2.42 \mathrm{E}-11$ & $8.33 \mathrm{E}-11$ & $1.25 \mathrm{E}-10$ & $1.82 \mathrm{E}-10$ & $2.53 \mathrm{E}-10$ & $3.87 \mathrm{E}-10$ & $5.46 \mathrm{E}-10$ \\
\hline $2.4 \ldots \ldots$ & $3.79 \mathrm{E}-12$ & $2.10 \mathrm{E}-11$ & $7.30 \mathrm{E}-11$ & $1.09 \mathrm{E}-10$ & $1.59 \mathrm{E}-10$ & $2.20 \mathrm{E}-10$ & $3.39 \mathrm{E}-10$ & $4.78 \mathrm{E}-10$ \\
\hline $2.5 \ldots \ldots$ & $3.25 \mathrm{E}-12$ & $1.82 \mathrm{E}-11$ & $6.40 \mathrm{E}-11$ & $9.66 \mathrm{E}-11$ & $1.38 \mathrm{E}-10$ & $1.92 \mathrm{E}-10$ & $2.96 \mathrm{E}-10$ & $4.18 \mathrm{E}-10$ \\
\hline $2.6 \ldots \ldots$ & $2.78 \mathrm{E}-12$ & $1.57 \mathrm{E}-11$ & $5.60 \mathrm{E}-11$ & $8.62 \mathrm{E}-11$ & $1.20 \mathrm{E}-10$ & $1.67 \mathrm{E}-10$ & $2.58 \mathrm{E}-10$ & $3.65 \mathrm{E}-10$ \\
\hline $2.7 \ldots \ldots$ & $2.38 \mathrm{E}-12$ & $1.36 \mathrm{E}-11$ & $4.89 \mathrm{E}-11$ & $7.79 \mathrm{E}-11$ & $1.05 \mathrm{E}-10$ & $1.45 \mathrm{E}-10$ & $2.25 \mathrm{E}-10$ & $3.19 \mathrm{E}-10$ \\
\hline $2.8 \ldots \ldots$ & $2.03 \mathrm{E}-12$ & $1.18 \mathrm{E}-11$ & $4.24 \mathrm{E}-11$ & $7.12 \mathrm{E}-11$ & $9.11 \mathrm{E}-11$ & $1.26 \mathrm{E}-10$ & $1.96 \mathrm{E}-10$ & $2.78 \mathrm{E}-10$ \\
\hline $2.9 \ldots \ldots$ & $1.73 \mathrm{E}-12$ & $1.03 \mathrm{E}-11$ & $3.67 \mathrm{E}-11$ & $6.55 \mathrm{E}-11$ & $7.91 \mathrm{E}-11$ & $1.09 \mathrm{E}-10$ & $1.70 \mathrm{E}-10$ & $2.43 \mathrm{E}-10$ \\
\hline 3.0. & $1.48 \mathrm{E}-12$ & $9.06 \mathrm{E}-12$ & $3.15 \mathrm{E}-11$ & $6.05 \mathrm{E}-11$ & $6.87 \mathrm{E}-11$ & $9.47 \mathrm{E}-11$ & $1.49 \mathrm{E}-10$ & $2.12 \mathrm{E}-10$ \\
\hline $3.1 .$. & $1.26 \mathrm{E}-12$ & $8.00 \mathrm{E}-12$ & $2.70 \mathrm{E}-11$ & $5.64 \mathrm{E}-11$ & $5.96 \mathrm{E}-11$ & $8.21 \mathrm{E}-11$ & $1.29 \mathrm{E}-10$ & $1.85 \mathrm{E}-10$ \\
\hline $3.2 \ldots$ & $1.07 \mathrm{E}-12$ & $7.09 \mathrm{E}-12$ & $2.31 \mathrm{E}-11$ & $5.32 \mathrm{E}-11$ & $5.16 \mathrm{E}-11$ & $7.12 \mathrm{E}-11$ & $1.12 \mathrm{E}-10$ & $1.61 \mathrm{E}-10$ \\
\hline $3.3 \ldots \ldots$ & $9.06 \mathrm{E}-13$ & $6.28 \mathrm{E}-12$ & $1.99 \mathrm{E}-11$ & $5.06 \mathrm{E}-11$ & $4.47 \mathrm{E}-11$ & $6.16 \mathrm{E}-11$ & $9.75 \mathrm{E}-11$ & $1.40 \mathrm{E}-10$ \\
\hline $3.4 \ldots \ldots$ & $7.68 \mathrm{E}-13$ & $5.55 \mathrm{E}-12$ & $1.74 \mathrm{E}-11$ & $4.84 \mathrm{E}-11$ & $7 E-11$ & $3 E-11$ & $8.47 \mathrm{E}-11$ & $1.22 \mathrm{E}-10$ \\
\hline $3.5 \ldots \ldots$ & $6.54 \mathrm{E}-13$ & $4.89 \mathrm{E}-12$ & $1.56 \mathrm{E}-11$ & $4.62 \mathrm{E}-11$ & $3.35 \mathrm{E}-11$ & $E-11$ & $7.35 \mathrm{E}-11$ & $1.06 \mathrm{E}-10$ \\
\hline $3.6 \ldots \ldots$ & $5.58 \mathrm{E}-13$ & $4.29 \mathrm{E}-12$ & $1.46 \mathrm{E}-11$ & $4.38 \mathrm{E}-11$ & $2.91 \mathrm{E}-11$ & $3.98 \mathrm{E}-11$ & $6.37 \mathrm{E}-11$ & $9.22 \mathrm{E}-11$ \\
\hline $3.7 \ldots \ldots$ & $4.79 \mathrm{E}-13$ & $3.75 \mathrm{E}-12$ & $1.41 \mathrm{E}-11$ & $4.11 \mathrm{E}-11$ & $2.57 \mathrm{E}-11$ & $3.44 \mathrm{E}-11$ & $5.52 \mathrm{E}-11$ & $8.01 \mathrm{E}-11$ \\
\hline $3.8 \ldots \ldots$ & $4.14 \mathrm{E}-13$ & $3.28 \mathrm{E}-12$ & $1.39 \mathrm{E}-11$ & $3.82 \mathrm{E}-11$ & $2.30 \mathrm{E}-11$ & $2.96 \mathrm{E}-11$ & $4.78 \mathrm{E}-11$ & $6.95 \mathrm{E}-11$ \\
\hline $3.9 \ldots \ldots$ & $3.60 \mathrm{E}-13$ & $2.87 \mathrm{E}-12$ & $1.37 \mathrm{E}-11$ & $3.52 \mathrm{E}-11$ & $2.11 \mathrm{E}-11$ & $2.55 \mathrm{E}-11$ & $4.13 \mathrm{E}-11$ & $6.03 \mathrm{E}-11$ \\
\hline $4.0 \ldots \ldots$ & $3.14 \mathrm{E}-13$ & $2.52 \mathrm{E}-12$ & $1.33 \mathrm{E}-11$ & $3.24 \mathrm{E}-11$ & $1.96 \mathrm{E}-11$ & $2.20 \mathrm{E}-11$ & $3.57 \mathrm{E}-11$ & $5.22 \mathrm{E}-11$ \\
\hline $4.1 \ldots \ldots$ & $2.75 \mathrm{E}-13$ & $2.21 \mathrm{E}-12$ & $1.26 \mathrm{E}-11$ & $2.98 \mathrm{E}-11$ & $1.85 \mathrm{E}-11$ & $1.89 \mathrm{E}-11$ & $3.08 \mathrm{E}-11$ & $4.53 \mathrm{E}-11$ \\
\hline 4.2. & $2.46 \mathrm{E}-13$ & $1.97 \mathrm{E}-12$ & $1.17 \mathrm{E}-11$ & $2.76 \mathrm{E}-11$ & $1.77 \mathrm{E}-11$ & $1.62 \mathrm{E}-11$ & $2.66 \mathrm{E}-11$ & $3.92 \mathrm{E}-11$ \\
\hline $4.3 \ldots$ & $2.49 \mathrm{E}-13$ & $1.83 \mathrm{E}-12$ & $1.07 \mathrm{E}-11$ & $2.58 \mathrm{E}-11$ & $1.81 \mathrm{E}-11$ & $1.38 \mathrm{E}-11$ & $2.29 \mathrm{E}-11$ & $3.39 \mathrm{E}-11$ \\
\hline $4.4 \ldots \ldots$ & $3.45 \mathrm{E}-13$ & $1.90 \mathrm{E}-12$ & $9.98 \mathrm{E}-12$ & $2.47 \mathrm{E}-11$ & $2.06 \mathrm{E}-11$ & $1.18 \mathrm{E}-11$ & $1.97 \mathrm{E}-11$ & $2.93 \mathrm{E}-11$ \\
\hline $4.5 \ldots \ldots$ & $6.26 \mathrm{E}-13$ & $2.42 \mathrm{E}-12$ & $1.01 \mathrm{E}-11$ & $2.59 \mathrm{E}-11$ & $2.60 \mathrm{E}-11$ & $1.01 \mathrm{E}-11$ & $1.70 \mathrm{E}-11$ & $2.53 \mathrm{E}-11$ \\
\hline $4.6 \ldots \ldots$ & $1.16 \mathrm{E}-12$ & $3.63 \mathrm{E}-12$ & $E-11$ & $3.20 \mathrm{E}-11$ & $3.36 \mathrm{E}-11$ & $E-12$ & $E-11$ & $2.18 \mathrm{E}-11$ \\
\hline $4.7 \ldots \ldots$ & $1.90 \mathrm{E}-12$ & $5.62 \mathrm{E}-12$ & $1.56 \mathrm{E}-11$ & $4.50 \mathrm{E}-11$ & $4.15 \mathrm{E}-11$ & $7.30 \mathrm{E}-12$ & $1.25 \mathrm{E}-11$ & $1.88 \mathrm{E}-11$ \\
\hline $4.8 \ldots \ldots$ & $2.72 \mathrm{E}-12$ & $8.17 \mathrm{E}-12$ & $2.13 \mathrm{E}-11$ & $6.39 \mathrm{E}-11$ & $4.74 \mathrm{E}-11$ & $6.19 \mathrm{E}-12$ & $1.07 \mathrm{E}-11$ & $1.62 \mathrm{E}-11$ \\
\hline $4.9 \ldots \ldots$ & $3.41 \mathrm{E}-12$ & $1.08 \mathrm{E}-11$ & $2.76 \mathrm{E}-11$ & $8.43 \mathrm{E}-11$ & $5.00 \mathrm{E}-11$ & $5.24 \mathrm{E}-12$ & $9.18 \mathrm{E}-12$ & $1.39 \mathrm{E}-11$ \\
\hline $5.0 \ldots \ldots$ & $3.84 \mathrm{E}-12$ & $1.30 \mathrm{E}-11$ & $3.32 \mathrm{E}-11$ & $1.01 \mathrm{E}-10$ & $4.91 \mathrm{E}-11$ & $4.43 \mathrm{E}-12$ & $7.85 \mathrm{E}-12$ & $1.19 \mathrm{E}-11$ \\
\hline $5.1 \ldots \ldots$ & $3.96 \mathrm{E}-12$ & $1.43 \mathrm{E}-11$ & $3.69 \mathrm{E}-11$ & $1.10 \mathrm{E}-10$ & $4.54 \mathrm{E}-11$ & $3.73 E-12$ & $6.70 \mathrm{E}-12$ & $1.03 \mathrm{E}-11$ \\
\hline $5.2 \ldots \ldots$ & $3.80 \mathrm{E}-12$ & $1.45 \mathrm{E}-11$ & $3.83 \mathrm{E}-11$ & $1.10 \mathrm{E}-10$ & $3.99 \mathrm{E}-11$ & $3.13 \mathrm{E}-12$ & $5.71 \mathrm{E}-12$ & $8.78 \mathrm{E}-12$ \\
\hline $5.3 \ldots$ & $3.44 \mathrm{E}-12$ & $1.38 \mathrm{E}-11$ & $3.74 \mathrm{E}-11$ & $1.03 \mathrm{E}-10$ & $3.39 \mathrm{E}-11$ & $2.63 \mathrm{E}-12$ & $4.86 \mathrm{E}-12$ & $7.51 \mathrm{E}-12$ \\
\hline $5.4 \ldots \ldots$ & $2.96 \mathrm{E}-12$ & $1.24 \mathrm{E}-11$ & $3.47 \mathrm{E}-11$ & $9.16 \mathrm{E}-11$ & $2.79 \mathrm{E}-11$ & $2.20 \mathrm{E}-12$ & $4.13 \mathrm{E}-12$ & $6.42 \mathrm{E}-12$ \\
\hline $5.5 \ldots \ldots$ & $2.46 \mathrm{E}-12$ & $1.07 \mathrm{E}-11$ & $3.08 \mathrm{E}-11$ & $7.77 \mathrm{E}-11$ & $2.25 \mathrm{E}-11$ & $1.83 \mathrm{E}-12$ & $3.50 \mathrm{E}-12$ & $5.48 \mathrm{E}-12$ \\
\hline $5.6 \ldots \ldots$ & $1.98 \mathrm{E}-12$ & $8.82 \mathrm{E}-12$ & $2.63 \mathrm{E}-11$ & $6.36 \mathrm{E}-11$ & $1.80 \mathrm{E}-11$ & $1.52 \mathrm{E}-12$ & $2.96 \mathrm{E}-12$ & $4.67 \mathrm{E}-12$ \\
\hline $5.7 \ldots \ldots$ & $1.55 \mathrm{E}-12$ & $7.10 \mathrm{E}-12$ & $2.18 \mathrm{E}-11$ & $5.06 \mathrm{E}-11$ & $1.42 \mathrm{E}-11$ & $1.26 \mathrm{E}-12$ & $2.50 \mathrm{E}-12$ & $3.97 \mathrm{E}-12$ \\
\hline $5.8 .$. & $1.20 \mathrm{E}-12$ & $5.57 \mathrm{E}-12$ & $1.76 \mathrm{E}-11$ & $3.94 \mathrm{E}-11$ & $1.10 \mathrm{E}-11$ & $1.05 \mathrm{E}-12$ & $2.11 \mathrm{E}-12$ & $3.37 \mathrm{E}-12$ \\
\hline $5.9 \ldots \ldots$ & $9.06 \mathrm{E}-13$ & $4.29 \mathrm{E}-12$ & $1.38 \mathrm{E}-11$ & $3.01 \mathrm{E}-11$ & $8.53 \mathrm{E}-12$ & $9.07 \mathrm{E}-13$ & $1.80 \mathrm{E}-12$ & $2.85 \mathrm{E}-12$ \\
\hline $6.0 \ldots \ldots$ & $6.79 \mathrm{E}-13$ & $3.25 \mathrm{E}-12$ & $1.07 \mathrm{E}-11$ & $2.26 \mathrm{E}-11$ & $6.55 \mathrm{E}-12$ & $8.77 \mathrm{E}-13$ & $1.57 \mathrm{E}-12$ & $2.40 \mathrm{E}-12$ \\
\hline $6.1 \ldots \ldots$ & $5.04 \mathrm{E}-13$ & $2.43 \mathrm{E}-12$ & $8.11 \mathrm{E}-12$ & $1.68 \mathrm{E}-11$ & $4.97 \mathrm{E}-12$ & $1.02 \mathrm{E}-12$ & $1.47 \mathrm{E}-12$ & $2.03 \mathrm{E}-12$ \\
\hline $6.2 \ldots \ldots$ & $3.71 \mathrm{E}-13$ & $1.80 \mathrm{E}-12$ & $6.08 \mathrm{E}-12$ & $1.24 \mathrm{E}-11$ & $3.76 \mathrm{E}-12$ & $1.35 \mathrm{E}-12$ & $1.52 \mathrm{E}-12$ & $1.71 \mathrm{E}-12$ \\
\hline $6.3 \ldots \ldots$ & $2.72 \mathrm{E}-13$ & $1.33 \mathrm{E}-12$ & $4.52 \mathrm{E}-12$ & $9.08 \mathrm{E}-12$ & $2.81 \mathrm{E}-12$ & $1.79 \mathrm{E}-12$ & $1.69 \mathrm{E}-12$ & $1.43 \mathrm{E}-12$ \\
\hline $6.4 \ldots \ldots$ & $1.98 \mathrm{E}-13$ & $9.70 \mathrm{E}-13$ & $3.32 \mathrm{E}-12$ & $6.61 \mathrm{E}-12$ & $2.09 \mathrm{E}-12$ & $2.22 \mathrm{E}-12$ & $1.92 \mathrm{E}-12$ & $1.20 \mathrm{E}-12$ \\
\hline $6.5 \ldots \ldots$ & $1.41 \mathrm{E}-13$ & $7.07 \mathrm{E}-13$ & $2.43 \mathrm{E}-12$ & $4.79 \mathrm{E}-12$ & $1.56 \mathrm{E}-12$ & $2.52 \mathrm{E}-12$ & $2.10 \mathrm{E}-12$ & $9.96 \mathrm{E}-13$ \\
\hline $6.6 \ldots \ldots$ & $1.02 \mathrm{E}-13$ & $5.05 \mathrm{E}-13$ & $1.77 \mathrm{E}-12$ & $3.46 \mathrm{E}-12$ & $1.15 \mathrm{E}-12$ & $2.63 \mathrm{E}-12$ & $2.18 \mathrm{E}-12$ & $8.27 \mathrm{E}-13$ \\
\hline $6.7 \ldots \ldots$ & $7.35 \mathrm{E}-14$ & $3.64 \mathrm{E}-13$ & $1.28 \mathrm{E}-12$ & $2.50 \mathrm{E}-12$ & $8.58 \mathrm{E}-13$ & $2.55 \mathrm{E}-12$ & $2.12 \mathrm{E}-12$ & $6.84 \mathrm{E}-13$ \\
\hline $6.8 \ldots \ldots$ & $5.27 \mathrm{E}-14$ & $2.63 \mathrm{E}-13$ & $9.24 \mathrm{E}-13$ & $1.80 \mathrm{E}-12$ & $6.33 E-13$ & $2.32 \mathrm{E}-12$ & $1.96 \mathrm{E}-12$ & $5.63 \mathrm{E}-13$ \\
\hline $6.9 \ldots \ldots$ & $3.78 \mathrm{E}-14$ & $1.89 \mathrm{E}-13$ & $6.59 \mathrm{E}-13$ & $1.30 \mathrm{E}-12$ & $4.72 \mathrm{E}-13$ & $2.01 \mathrm{E}-12$ & $1.72 \mathrm{E}-12$ & $4.61 \mathrm{E}-13$ \\
\hline $7.0 \ldots \ldots$ & $2.72 \mathrm{E}-14$ & $1.35 \mathrm{E}-13$ & $4.73 \mathrm{E}-13$ & $9.00 \mathrm{E}-13$ & $3.53 \mathrm{E}-13$ & $1.68 \mathrm{E}-12$ & $1.46 \mathrm{E}-12$ & $3.75 \mathrm{E}-13$ \\
\hline $7.1 \ldots \ldots$ & $1.95 \mathrm{E}-14$ & $9.69 \mathrm{E}-14$ & $3.39 \mathrm{E}-13$ & $6.43 \mathrm{E}-13$ & $2.36 \mathrm{E}-13$ & $1.36 \mathrm{E}-12$ & $1.20 \mathrm{E}-12$ & $3.05 \mathrm{E}-13$ \\
\hline $7.2 \ldots \ldots$ & $1.40 \mathrm{E}-14$ & $6.95 \mathrm{E}-14$ & $2.42 \mathrm{E}-13$ & $4.60 \mathrm{E}-13$ & $1.75 \mathrm{E}-13$ & $1.07 \mathrm{E}-12$ & $9.52 \mathrm{E}-13$ & $2.45 \mathrm{E}-13$ \\
\hline $7.3 \ldots \ldots$ & $1.00 \mathrm{E}-14$ & $4.98 \mathrm{E}-14$ & $1.73 \mathrm{E}-13$ & $3.26 \mathrm{E}-13$ & $1.30 \mathrm{E}-13$ & $8.22 \mathrm{E}-13$ & $7.43 \mathrm{E}-13$ & $1.96 \mathrm{E}-13$ \\
\hline
\end{tabular}


TABLE 3-Continued

\begin{tabular}{|c|c|c|c|c|c|c|c|c|}
\hline \multirow[b]{3}{*}{$\log _{10} T$} & \multicolumn{8}{|c|}{$\alpha_{R}(T)$} \\
\hline & O I & $\mathrm{O}$ II & $\mathrm{O}$ III & O IV & $\mathrm{O} \mathrm{v}$ & O vI & O vil & \\
\hline & 5.4 & 5.6 & 5.9 & 5.9 & 6.1 & 6.9 & 7.0 & O vIII \\
\hline $7.4 .$. & $7.19 \mathrm{E}-15$ & $3.57 \mathrm{E}-14$ & $1.23 \mathrm{E}-13$ & $2.33 E-13$ & $9.50 \mathrm{E}-14$ & $6.24 \mathrm{E}-13$ & $5.72 \mathrm{E}-13$ & $1.57 \mathrm{E}-13$ \\
\hline $7.5 \ldots \ldots$ & $5.16 \mathrm{E}-15$ & $2.55 \mathrm{E}-14$ & $8.81 \mathrm{E}-14$ & $1.66 \mathrm{E}-13$ & $7.10 \mathrm{E}-14$ & $4.68 \mathrm{E}-13$ & $4.33 \mathrm{E}-13$ & $1.24 \mathrm{E}-13$ \\
\hline $7.6 \ldots \ldots$ & $3.71 \mathrm{E}-15$ & $1.83 \mathrm{E}-14$ & $6.29 \mathrm{E}-14$ & $1.19 \mathrm{E}-13$ & $5.31 \mathrm{E}-14$ & $3.47 \mathrm{E}-13$ & $3.26 \mathrm{E}-13$ & $9.76 \mathrm{E}-14$ \\
\hline $7.7 \ldots \ldots$ & $2.67 \mathrm{E}-15$ & $1.31 \mathrm{E}-14$ & $4.48 \mathrm{E}-14$ & $8.48 \mathrm{E}-14$ & $3.99 \mathrm{E}-14$ & $2.56 \mathrm{E}-13$ & $2.43 E-13$ & $7.63 \mathrm{E}-14$ \\
\hline $7.8 \ldots \ldots$ & $1.92 \mathrm{E}-15$ & $9.41 \mathrm{E}-15$ & $3.20 \mathrm{E}-14$ & $6.06 \mathrm{E}-14$ & $3.00 \mathrm{E}-14$ & $1.88 \mathrm{E}-13$ & $1.80 \mathrm{E}-13$ & $5.93 \mathrm{E}-14$ \\
\hline $7.9 \ldots \ldots$ & $1.39 \mathrm{E}-15$ & $6.76 \mathrm{E}-15$ & $2.28 \mathrm{E}-14$ & $4.34 \mathrm{E}-14$ & $2.26 \mathrm{E}-14$ & $1.32 \mathrm{E}-13$ & $1.33 \mathrm{E}-13$ & $4.59 \mathrm{E}-14$ \\
\hline $8.0 \ldots \ldots$ & $1.00 \mathrm{E}-15$ & $4.86 \mathrm{E}-15$ & $1.63 \mathrm{E}-14$ & $3.11 \mathrm{E}-14$ & $1.71 \mathrm{E}-14$ & $9.59 \mathrm{E}-14$ & $9.42 \mathrm{E}-14$ & $3.51 \mathrm{E}-14$ \\
\hline $8.1 \ldots \ldots$ & $7.27 \mathrm{E}-16$ & $3.50 \mathrm{E}-15$ & $1.16 \mathrm{E}-14$ & $2.23 \mathrm{E}-14$ & $1.29 \mathrm{E}-14$ & $6.93 \mathrm{E}-14$ & $6.89 \mathrm{E}-14$ & $2.70 \mathrm{E}-14$ \\
\hline $8.2 \ldots \ldots$ & $5.29 \mathrm{E}-16$ & $2.53 \mathrm{E}-15$ & $8.30 \mathrm{E}-15$ & $1.61 \mathrm{E}-14$ & $9.76 \mathrm{E}-15$ & $4.96 \mathrm{E}-14$ & $5.03 \mathrm{E}-14$ & $2.05 \mathrm{E}-14$ \\
\hline $8.3 \ldots \ldots$ & $3.87 \mathrm{E}-16$ & $1.83 \mathrm{E}-15$ & $5.93 \mathrm{E}-15$ & $1.16 \mathrm{E}-14$ & $7.40 \mathrm{E}-15$ & $3.57 \mathrm{E}-14$ & $3.63 \mathrm{E}-14$ & $1.55 \mathrm{E}-14$ \\
\hline $8.4 \ldots \ldots$ & $2.85 \mathrm{E}-16$ & $1.33 \mathrm{E}-15$ & $4.25 \mathrm{E}-15$ & $8.40 \mathrm{E}-15$ & $5.62 \mathrm{E}-15$ & $2.57 \mathrm{E}-14$ & $2.64 \mathrm{E}-14$ & $1.16 \mathrm{E}-14$ \\
\hline $8.5 \ldots \ldots$ & $2.11 \mathrm{E}-16$ & $9.71 \mathrm{E}-16$ & $3.04 \mathrm{E}-15$ & $6.11 \mathrm{E}-15$ & $4.28 \mathrm{E}-15$ & $1.85 \mathrm{E}-14$ & $1.91 \mathrm{E}-14$ & $8.72 \mathrm{E}-15$ \\
\hline $8.6 \ldots \ldots$ & $1.57 \mathrm{E}-16$ & $7.12 \mathrm{E}-16$ & $2.18 \mathrm{E}-15$ & $4.47 \mathrm{E}-15$ & $3.27 \mathrm{E}-15$ & $1.33 \mathrm{E}-14$ & $1.39 \mathrm{E}-14$ & $6.51 \mathrm{E}-15$ \\
\hline $8.7 \ldots \ldots$ & $1.18 \mathrm{E}-16$ & $5.25 \mathrm{E}-16$ & $1.57 \mathrm{E}-15$ & $3.29 \mathrm{E}-15$ & $2.51 \mathrm{E}-15$ & $9.55 \mathrm{E}-15$ & $1.01 \mathrm{E}-14$ & $4.83 \mathrm{E}-15$ \\
\hline $8.8 \ldots \ldots$ & $8.97 \mathrm{E}-17$ & $3.89 \mathrm{E}-16$ & $1.13 \mathrm{E}-15$ & $2.43 \mathrm{E}-15$ & $1.93 \mathrm{E}-15$ & $6.87 \mathrm{E}-15$ & $7.31 \mathrm{E}-15$ & $3.58 \mathrm{E}-15$ \\
\hline $8.9 \ldots \ldots$ & $6.88 \mathrm{E}-17$ & $2.91 \mathrm{E}-16$ & $8.20 \mathrm{E}-16$ & $1.82 \mathrm{E}-15$ & $1.50 \mathrm{E}-15$ & $4.95 \mathrm{E}-15$ & $5.30 \mathrm{E}-15$ & $2.64 \mathrm{E}-15$ \\
\hline $9.0 \ldots \ldots$ & $5.33 \mathrm{E}-17$ & $2.20 \mathrm{E}-16$ & $5.96 \mathrm{E}-16$ & $1.37 \mathrm{E}-15$ & $1.17 \mathrm{E}-15$ & $3.58 \mathrm{E}-15$ & $3.85 \mathrm{E}-15$ & $1.93 \mathrm{E}-15$ \\
\hline
\end{tabular}

a Total recombination rate coefficients, $\alpha_{R}(T)$ (in units of $\mathrm{cm}^{3} \mathrm{~s}^{-1}$ ), for the oxygen ions, $\mathrm{O} \mathrm{I}-\mathrm{O}$ VIII, in the temperature range $1.0 \leq \log _{10} T \leq 9.0 \mathrm{~K}$. Rates correspond to extrapolated photoionization cross sections beyond temperature $T_{0}$. The figure given below the name of the ion is $\log _{10} T_{0}$.

result of DR and dominates at high temperatures, producing a large bump that is followed by monotonic decay. The feature is seen in the top panels of Figures $4 a-4 g$, where the total $\alpha_{R}(T)$ are presented (solid curves). Superimposed on this general pattern may be a small low-temperature "bump" due to the near-threshold autoionizing resonances in the photoionization cross sections. This low-temperature bump (first discussed by Nussbaumer \& Storey 1983) is distinctly seen in the $\alpha_{R}(T)$ for O III (Fig. 4c) and O IV (Fig. $4 d$ ). At very low temperatures, the low-energy electron is captured by the target ion through direct nonresonant recombination to the infinite number of recombined states, giving almost a straight-line shape for $\log _{10} \alpha_{R}(T)$ in the low-temperature region. However, the line shape changes with increasing electron energy when the target ion is excited via the DR process introducing resonances in the cross sections. At higher temperatures, recombination is dominated mainly by the DR process, which causes a rise in $\alpha_{R}(T)$ and a well-defined bump.

Present total recombination rates are compared with the previously calculated ones in Figures $4 a-4 g$. In the top panels of Figs. $4 a-4 f$, the dashed curves are the RR rate coefficients of Péquignot, Petitjean, \& Boisson (1991); the dotted curves are the low-temperature DR rate coefficients by Nussbaumer \& Storey (1983); the dot-dashed and dashchained curves are respectively the high-temperature DR rate coefficients of Jacobs et al. (1977; fitted by Shull \& van Steenberg 1982; values are fitted from the works of Jacobs et al. 1977 as referenced in Shull \& van Steenberg) and Badnell \& Pindzola (1989) and Badnell, Pindzola, \& Griffin (1990) obtained using different approximations. Péquignot et al. (1991) calculated the RR rates from photoionization cross sections with some or no resonances, and hydrogenic or extrapolated cross sections. The low-temperature DR rates by Nussbaumer \& Storey (1983) are obtained through atomic structure calculations. The high-temperature DR rates in the previous works are obtained in the isolated resonance approximation, such as using the distorted-wave approximation (e.g., Jacobs et al. 1977; references in Shull \& van Steenberg 1982; Badnell \& Pindzola 1989; Badnell et al. 1990) that couples only the initial and the final states. Based on currently available data, the total recombination rates are obtained as the sum of the RR and the low- and high-temperature DR rates. In the lower panels of Figures $4 a-4 \mathrm{~g}$, comparisons are made of the present total, unified rates (solid curves) with the sum of the individual RR, low- $T$ $\mathrm{DR}$, and high- $T$ DR rates from earlier works (dotted curves) in the temperature region where $\alpha_{R}(T)$ goes through minimum, around temperatures of maximum abundance of the given ions. In sum, the high-temperature DR contributions are taken from the fitting formulae of Shull \& van Steenberg (1982).

The present total recombination rate coefficients for O I agree very well with the earlier works, except in the hightemperature region where the earlier rates are much higher. The reason could be the effect of autoionization into excited states, an effect first discussed by Jacobs et al. (1977). Autoionization is treated more precisely in the present work where autoionization into all target ion states is included through channel couplings. A similar trend is seen for $\mathrm{O}$ II at higher temperatures; some significant differences are seen at low temperatures as well. For $\mathrm{O}$ III, the present rates reproduce the low-temperature DR bump obtained by Nussbaumer \& Storey; however, the total rates show differences increasing with temperature. The agreement of the present rates at high temperatures is better with those of Badnell \& Pindzola (1989). A comparatively large difference is noted for O IV, where (assuming no numerical error in the tabulation by Nussbaumer \& Storey 1983) the earlier lowtemperature rates are considerably overestimated. At higher temperatures, both the fitted values of $\alpha_{R}$ by Shull $\&$ van Steenberg (1982) and the DR rates computed by Badnell et al. (1990) are lower than the present values. For O v, generally good agreement is found between the present and the sum of RR, low-temperature DR, and high-temperature DR rates from earlier works, except at high temperatures where 

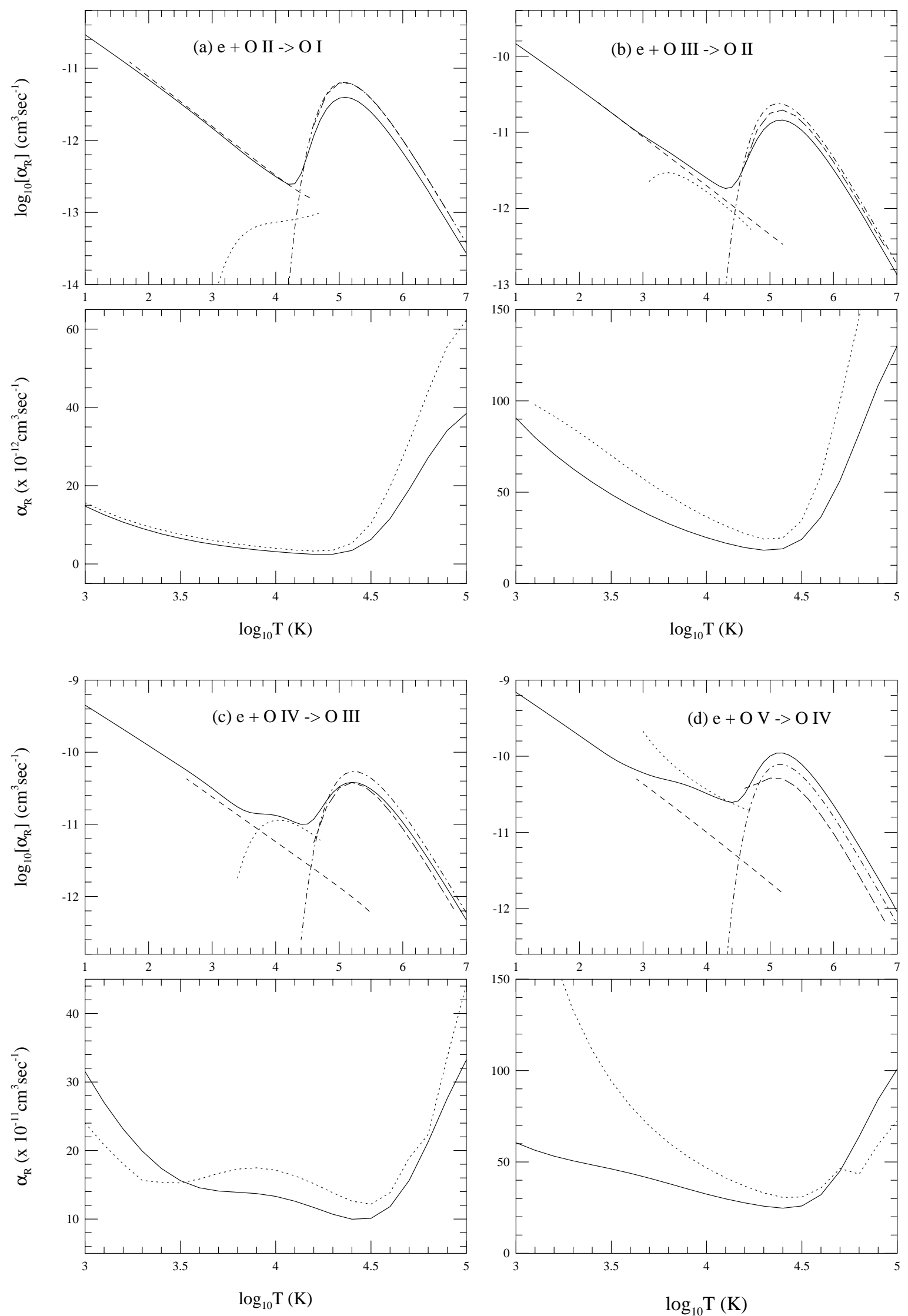

FIG. 4.-Present total recombination rate coefficients, $\alpha_{R}(T)$, of $(a) \mathrm{O}$ I, $(b) \mathrm{O}$ II, $(c) \mathrm{O}$ III, $(d) \mathrm{O}$ IV, $(e) \mathrm{O}$ v, $(f) \mathrm{O}$ vI, and $(g) \mathrm{O}$ vII (solid curves). In the upper panels, the dashed curves are the RR rates calculated by Péquignot et al. (1991), the dotted curves are the low-temperature DR rates by Nussbaumer \& Storey (1983), the dot-chained and the dash-chained curves are the high-temperature DR rates by Jacobs et al. (1977) fitted respectively by Shull \& van Steenberg (1982) and by Badnell \& Pindzola (1989) and Badnell et al. (1990). In $(g)$ the dotted curve in the upper panel and the dashed curve in the lower panel are present total $\alpha_{R}(T)$ in $L S$ coupling, while the solid curves are those in the Breit-Pauli approximation including radiation damping. In all lower panels, present total $\alpha_{R}(T)$ values are compared with the summed rates (dotted curves) of earlier works. 

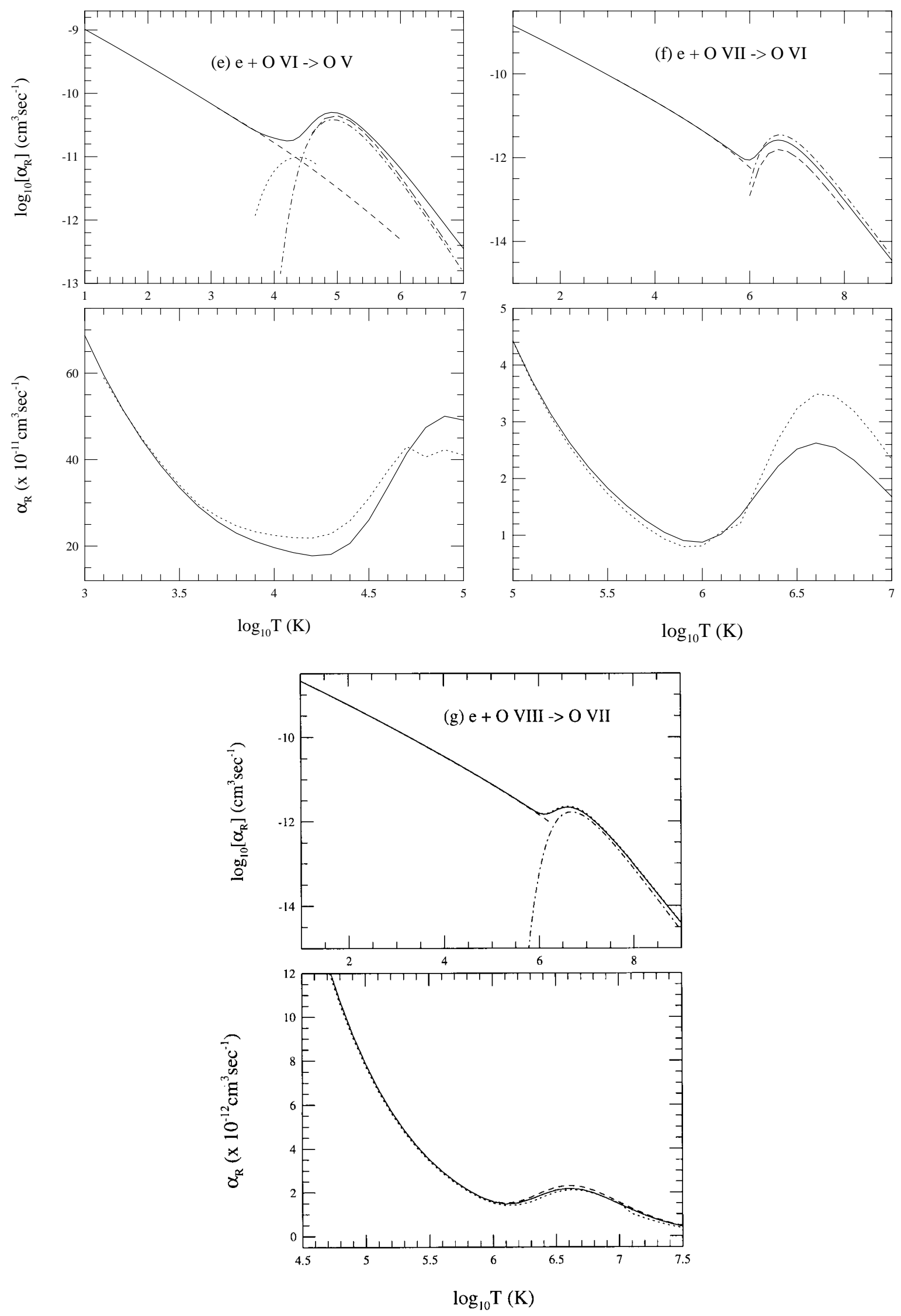

FIG. 4.-Continued 
earlier rates are somewhat lower. Quite good agreement between the two sets of values can be found for $\mathrm{O}$ vi; however, at the temperatures where DR dominates, the present values lie between those of Shull \& van Steenberg and those of Badnell et al.

Values of the total recombination rate, $\alpha_{R}(T)$, of $\mathrm{O}$ VII from $\mathrm{O}$ VIII are obtained in both the $L S$ coupling and the BP approximation with relativistic fine structure. Further, the effect of radiation damping of resonances is included as discussed in the above section (Pradhan \& Zhang 1997; Zhang et al. 1998). The rates are presented in Figure $4 g$. The two sets of total, unified rates, (1) in $L S$ coupling (Fig. $4 g$, dotted curve in the top panels; dashed curve in the bottom panels), and (2) in the BP approximation with radiation damping (Fig. 4g, solid curve in both panels), agree very well with each other, and with the sum of the individual rates from earlier works by Péquignot et al. (1991) and by Shull \& van Steenberg (1982). The BP rates correspond to a larger number of bound states, and more resonance structures due to fine-structure splitting of target terms in intermediate coupling. The BP rates without the radiation damping effect are larger than those in $L S$ coupling. However, inclusion of the damping of resonances reduces these rates back to roughly those in $L S$ coupling; the maximum difference between the two sets is only about $6 \%$ at $\log _{10} T=6.5 \mathrm{~K}$. Although somewhat fortuitous, the present $L S$ coupling rates do not differ significantly from the relativistic calculations with radiation damping; the fine-structure and resonance damping operate in an opposite manner. We expect, therefore, that the results for He-like $\mathrm{O}$ VII, as well as for $\mathrm{C} \mathrm{V}$ and $\mathrm{N}$ VI reported earlier (Nahar \& Pradhan 1997), should be accurate.

\subsection{Ionization Fractions}

Determination of ionization fractions in plasmas requires the total recombination rate coefficients, $\alpha_{R}(T)$, for all ionization stages. Present total recombination rate coefficients for the oxygen ions are used to compute ionization fractions, $\log \left[N(z) / N_{T}\right]$, in collisional equilibrium. The numerical values are presented in Table 4 and are plotted in Figure 5 (solid curves).

The most recent values of oxygen ionization fractions in coronal equilibrium were calculated by Sutherland \& Dopita (1993), who used radiative recombination (RR) rates by Aldrovandi \& Péquignot (1973) and low-temperature dielectronic recombination rates by Nussbaumer \& Storey

TABLE 4

Ionization Fractions, $-\log _{10}\left[N(z) / N_{T}\right]$, of Oxygen Ions IN the Coronal Equilibrium

\begin{tabular}{|c|c|c|c|c|c|c|c|c|c|}
\hline \multirow[b]{2}{*}{$\log _{10} T$} & \multicolumn{9}{|c|}{$-\log _{10}\left[N(z) / N_{T}\right]$} \\
\hline & $\mathrm{O}_{\mathrm{I}}$ & $\mathrm{O}$ II & $\mathrm{O}$ III & $\mathrm{O}$ IV & $\mathrm{O} v$ & $\mathrm{O}$ VI & O VII & O VIII & O IX \\
\hline $4.0 \ldots \ldots$ & 0.001 & 2.500 & $\ldots$ & $\ldots$ & $\ldots$ & $\cdots$ & $\ldots$ & $\ldots$ & $\ldots$ \\
\hline $4.1 \ldots \ldots$ & 0.043 & 1.020 & $\ldots$ & $\ldots$ & $\ldots$ & $\ldots$ & $\ldots$ & $\ldots$ & $\ldots$ \\
\hline $4.2 \ldots \ldots$ & 0.432 & 0.200 & 7.910 & $\ldots$ & $\ldots$ & $\ldots$ & $\ldots$ & $\ldots$ & $\ldots$ \\
\hline $4.3 \ldots \ldots$ & 1.190 & 0.029 & 5.370 & $\cdots$ & $\cdots$ & $\ldots$ & $\ldots$ & $\cdots$ & $\cdots$ \\
\hline $4.4 \ldots \ldots$ & 1.770 & 0.008 & 3.490 & $\ldots$ & $\ldots$ & $\ldots$ & $\ldots$ & $\ldots$ & $\ldots$ \\
\hline $4.5 \ldots \ldots$ & 2.120 & 0.007 & 2.100 & 8.150 & $\ldots$ & $\ldots$ & $\ldots$ & $\ldots$ & $\ldots$ \\
\hline $4.6 \ldots \ldots$ & 2.380 & 0.037 & 1.110 & 5.380 & $\ldots$ & $\ldots$ & $\ldots$ & $\ldots$ & $\ldots$ \\
\hline $4.7 \ldots \ldots$ & 2.720 & 0.176 & 0.481 & 3.390 & 9.730 & $\ldots$ & $\ldots$ & $\ldots$ & $\ldots$ \\
\hline $4.8 \ldots \ldots$ & 3.210 & 0.483 & 0.179 & 2.050 & 6.890 & $\ldots$ & $\ldots$ & $\ldots$ & $\ldots$ \\
\hline $4.9 \ldots \ldots$ & 3.820 & 0.901 & 0.096 & 1.140 & 4.760 & $\ldots$ & $\ldots$ & $\ldots$ & $\ldots$ \\
\hline $5.0 \ldots \ldots$ & 4.520 & 1.400 & 0.174 & 0.539 & 3.170 & 7.540 & $\ldots$ & $\ldots$ & $\ldots$ \\
\hline $5.1 \ldots \ldots$ & 5.330 & 2.010 & 0.417 & 0.223 & 2.020 & 5.130 & 8.580 & $\ldots$ & $\ldots$ \\
\hline $5.2 \ldots \ldots$ & 6.220 & 2.710 & 0.778 & 0.114 & 1.210 & 3.280 & 5.480 & $\ldots$ & $\ldots$ \\
\hline $5.3 \ldots \ldots$ & 7.160 & 3.450 & 1.220 & 0.155 & 0.646 & 1.870 & 3.040 & $\ldots$ & $\ldots$ \\
\hline $5.4 \ldots \ldots$ & 8.230 & 4.320 & 1.820 & 0.410 & 0.387 & 0.895 & 1.240 & $\ldots$ & $\ldots$ \\
\hline $5.5 \ldots \ldots$ & 9.780 & 5.670 & 2.920 & 1.200 & 0.724 & 0.634 & 0.289 & $\begin{array}{l}\cdots \\
\ldots\end{array}$ & $\cdots$ \\
\hline $5.6 \ldots \ldots$ & $\ldots$ & 7.430 & 4.430 & 2.430 & 1.570 & 0.975 & 0.064 & 8.430 & $\ldots$ \\
\hline $5.7 \ldots \ldots$ & $\ldots$ & 9.110 & 5.890 & 3.640 & 2.430 & 1.400 & 0.019 & 6.350 & $\ldots$ \\
\hline $5.8 \ldots \ldots$ & $\ldots$ & $\ldots$ & 7.190 & 4.710 & 3.180 & 1.780 & 0.008 & 4.680 & $\ldots$ \\
\hline $5.9 \ldots \ldots$ & $\ldots$ & $\ldots$ & 8.330 & 5.620 & 3.820 & 2.100 & 0.004 & 3.330 & 7.880 \\
\hline $6.0 \ldots \ldots$ & $\ldots$ & $\ldots$ & 9.290 & 6.390 & 4.330 & 2.320 & 0.005 & 2.240 & 5.540 \\
\hline $6.1 \ldots \ldots$ & $\ldots$ & $\ldots$ & $\ldots$ & 7.000 & 4.700 & 2.440 & 0.020 & 1.390 & 3.670 \\
\hline $6.2 \ldots \ldots$ & $\begin{array}{l}\cdots \\
\ldots\end{array}$ & $\begin{array}{l}\cdots \\
\cdots\end{array}$ & $\begin{array}{l}\cdots \\
\cdots\end{array}$ & 7.520 & 5.010 & 2.510 & 0.080 & 0.795 & 2.240 \\
\hline $6.3 \ldots \ldots$ & $\ldots$ & $\ldots$ & $\ldots$ & 8.090 & 5.360 & 2.660 & 0.236 & 0.450 & 1.210 \\
\hline $6.4 \ldots \ldots$ & $\ldots$ & $\ldots$ & $\ldots$ & 8.770 & 5.860 & 2.960 & 0.538 & 0.364 & 0.559 \\
\hline $6.5 \ldots \ldots$ & $\ldots$ & $\ldots$ & $\ldots$ & 9.620 & 6.530 & 3.440 & 1.000 & 0.508 & 0.229 \\
\hline $6.6 \ldots \ldots$ & $\ldots$ & $\ldots$ & $\ldots$ & $\ldots$ & 7.280 & 4.030 & 1.550 & 0.772 & 0.096 \\
\hline $6.7 \ldots \ldots$ & $\cdots$ & $\cdots$ & $\cdots$ & $\cdots$ & 8.040 & 4.620 & 2.080 & 1.060 & 0.044 \\
\hline $6.8 \ldots \ldots$ & $\ldots$ & $\ldots$ & $\ldots$ & $\ldots$ & 8.770 & 5.200 & 2.580 & 1.330 & 0.022 \\
\hline $6.9 \ldots \ldots$ & $\ldots$ & $\ldots$ & $\ldots$ & $\ldots$ & 9.460 & 5.750 & 3.040 & 1.570 & 0.012 \\
\hline $7.0 \ldots \ldots$ & $\ldots$ & $\ldots$ & $\ldots$ & $\ldots$ & $\ldots$ & 6.270 & 3.450 & 1.790 & 0.007 \\
\hline $7.1 \ldots \ldots$ & $\ldots$ & $\ldots$ & $\ldots$ & $\ldots$ & $\ldots$ & 6.760 & 3.840 & 1.980 & 0.005 \\
\hline $7.2 \ldots \ldots$ & $\ldots$ & $\ldots$ & $\ldots$ & $\ldots$ & $\ldots$ & 7.250 & 4.200 & 2.160 & 0.003 \\
\hline $7.3 \ldots \ldots$ & $\ldots$ & $\ldots$ & $\ldots$ & $\ldots$ & $\ldots$ & 7.700 & 4.530 & 2.320 & 0.002 \\
\hline $7.4 \ldots \ldots$ & $\begin{array}{l}\cdots \\
\ldots\end{array}$ & $\begin{array}{l}\cdots \\
\ldots\end{array}$ & $\begin{array}{l}\cdots \\
\ldots\end{array}$ & $\begin{array}{l}\cdots \\
\cdots\end{array}$ & $\cdots$ & 8.130 & 4.850 & 2.470 & 0.001 \\
\hline $7.5 \ldots \ldots$ & $\ldots$ & $\ldots$ & $\ldots$ & $\ldots$ & $\ldots$ & 8.560 & 5.150 & 2.610 & 0.001 \\
\hline
\end{tabular}




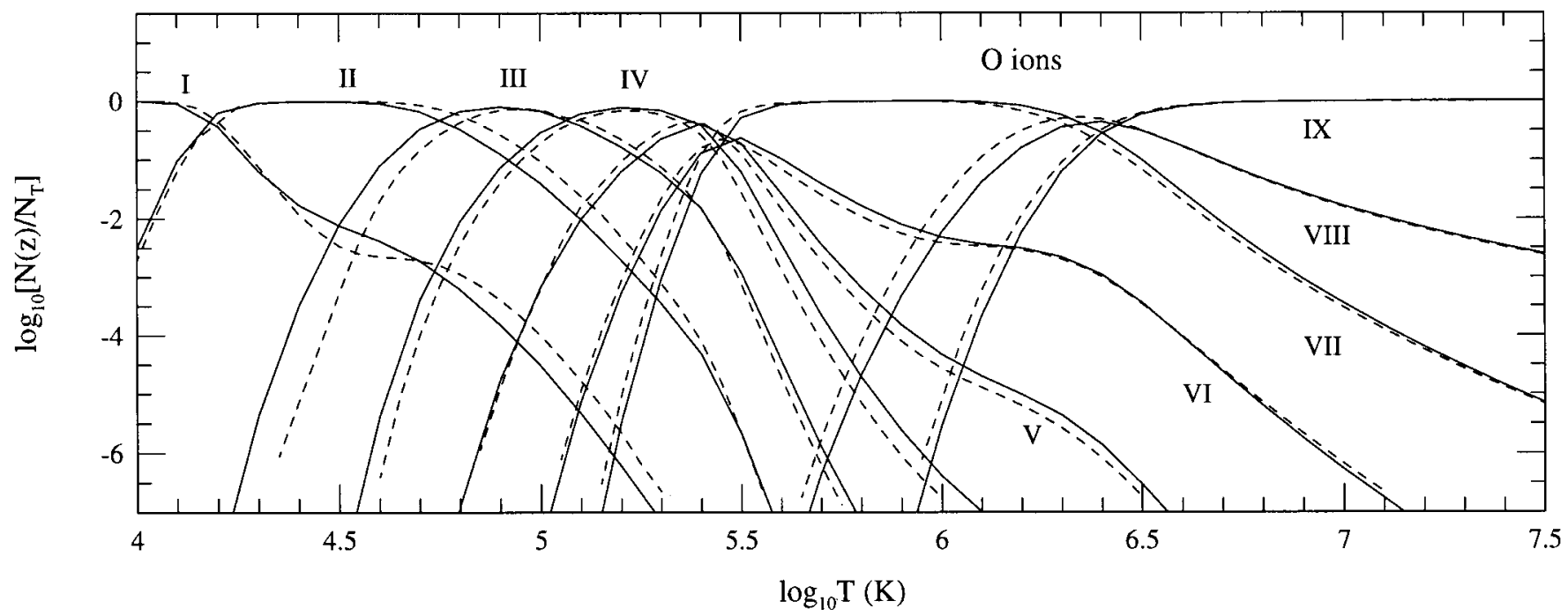

FIG. 5.- Ionization fractions, $N(z) / N_{T}$, of oxygen ions: solid curves are obtained using the present total electron-ion recombination rate coefficients, and the dashed curves are those by Sutherland \& Dopita (1993).

(1984). The RR rates of Aldrovandi \& Péquignot (1973) were obtained from photoionization cross sections calculated in central field and hydrogenic approximations, and are very close to those of Péquignot et al. (1991). Differences between the earlier and present rates are discussed in the previous section. These will be reflected in applications such as the calculation of ionization fractions. Sutherland \& Dopita (1993) used electron-impact ionization rates obtained from fitting methods of Younger (1981, 1982, 1983) and atomic data referred to in Arnaud \& Rothenflug (1985). As mentioned earlier, the present work obtains these rates from the latest compilation with recommended data by Bell et al. (1983). The ionization fractions obtained by Sutherland \& Dopita (1993) agree well with those by Arnaud \& Rothenflug (1985).

Present ionization fractions are compared with those of Sutherland \& Dopita (1993) (dashed curves) in Figure 5. The basic features in the two sets of values are similar; however, there are significant differences in the numerical values, particularly at the transition boundaries between adjacent ionization stages. The depth of the "dip," and the high-temperature behavior of the $\mathrm{O}$ I ion fraction, in the present results differ from the results of Sutherland \& Dopita (1993). Significant differences are seen in several other cases, such as for $\mathrm{O}$ II, $\mathrm{O}$ III, and $\mathrm{O}$ vIII, at temperatures when the ionic abundance is comparatively high. In comparison with currently available data, the present recombination rates imply a faster decrease in the abundance of $\mathrm{O}$ II with temperature, while that of $\mathrm{O}$ III and $\mathrm{O}$ VIII rises faster with temperature in coronal plasmas. These differences could affect the computation of ionization balance and spectral line intensities in astrophysical models.

\section{CONCLUSION}

Self-consistent sets of data are obtained for photoionization cross sections, $\sigma_{\mathrm{PI}}$, and unified, total recombination rate coefficients, $\alpha_{R}(T)$, for the oxygen ions. These may be directly applied to astrophysical and laboratory plasma modeling. State-specific recombination rates and partial photoionization cross sections are also presented for a large number of bound states for each ion. The overall uncertainty in the electron-ion recombination data is estimated to be the same as usually assessed for close coupling calculations for light atomic systems, $10 \%-20 \%$, based on the agreement with the measured energies and oscillator strengths. Some detailed comparisons of photorecombination cross sections with experimentally measured values in storage rings and ion traps also confirm this assessment (Zhang et al. 1998). The comparison of the present ionization fractions with previous works shows good agreement in basic features; however, some significant differences are found at temperatures corresponding to transitions between certain ionization stages, with possible effects in transient plasmas.

All photoionization and recombination data are available electronically from the author at nahar@astronomy.ohio-state.edu.

The author would like to thank Professor Anil K. Pradhan for contributions (supported partially by grants from NSF and NASA). Part of the computational work was carried out on the Cray Y-MP at the Ohio Supercomputer Center.
Aldrovandi, S. M. V., \& Péquignot, D. 1973, A\&A, 25, 137

Arnaud, M., \& Rothenflug, R. 1985, A\&AS, 60, 425

Badnell, N. R., \& Pindzola, M. S. 1989, Phys. Rev. A, 39, 1690

Badnell, N. R., Pindzola, M. S., \& Griffin, D. C. 1990, Phys. Rev. A, 41, 2422

Bell, K. L., Gilbody, H. B., Hughes, J. G., Kingston, A. E., \& Smith, F. J. 1983, J. Phys. Chem. Ref. Data, 12(4), 891

Bell, R. H., \& Seaton, M. J. 1985, J. Phys. B, 18, 1589

Berrington, K. A., Burke, P. G., Butler, K., Seaton, M. J., Storey, P. J.,

Taylor, K. T., \& Yan, Yu. 1987, J. Phys. B, 20, 6379

\section{REFERENCES}

Hummer, D. G., Berrington, K. A., Eissner, W., Pradhan, A. K., Saraph, H. E., \& Tully, J. A. 1993, A\&A, 279, 298

Jacobs, V. L., Davis, J., Kepple, P. C., \& Blaha, M. 1977, ApJ, 211, 605

Nahar, S. N. 1995, ApJS, 101, 423 1996a, ApJS, 106, 213

1996b, Phys. Rev. A, 53, 2417 1998, Phys. Rev. A, 58, 3766

Nahar, S. N., \& Pradhan, A. K. 1994, Phys. Rev. A, 49, 1816 (NP2) 1995, ApJ, 447, 966 (NP3)

1997, ApJS, 111, 339 (NP1) 
Nussbaumer, H., \& Storey, P. J. 1983, A\&A, 126, 75 1984, A\&AS, 56, 293

Péquignot, D., Petitjean, P., \& Boisson, C. 1991, A\&A, 251, 680

Pradhan, A. K., \& Zhang, H. L. 1997, J. Phys. B, 30, L571

Reilman, R. F., \& Manson, S. T. 1979, ApJS, 40, 815

Scott, N. S., \& Taylor, K. T. 1982, Comput. Phys. Commun., 25, 347

Seaton, M. J. 1987, J. Phys. B, 20, 6363

Shull, J. M., \& van Steenberg, M. 1982, ApJS, 48, 95
Sutherland, R. S., \& Dopita, M. A. 1993, ApJS, 88, 253

Yan, Y., \& Seaton, M. J. 1987, J. Phys. B, 20, 6409

Younger, S. M. 1981, J. Quant. Spectrosc. Radiat. Transfer, 26, 329

Younger, S. M. 1982, J. Quant. Spectrosc. Radiat. Transfer, 27, 541 1983, J. Quant. Spectrosc. Radiat. Transfer, 29, 61

Zhang, H. L., Nahar, S. N., \& Pradhan, A. K. 1998, J. Phys. B, submitted Zhang, H. L., \& Pradhan, A. K. 1997, Phys. Rev. Lett., 78, 195 